\title{
The contributions of local and remote atmospheric moisture fluxes to East Asian precipitation and its variability
}

\author{
Liang Guo ${ }^{1}$ (D) Nicholas P. Klingaman ${ }^{1} \cdot$ Marie-Estelle Demory ${ }^{1,3} \cdot$ Pier Luigi Vidale $^{1} \cdot$ Andrew G. Turner $^{1,2}$. \\ Claudia C. Stephan ${ }^{1}$
}

Received: 22 May 2017 / Accepted: 24 December 2017 / Published online: 13 January 2018

(c) The Author(s) 2018. This article is an open access publication

\begin{abstract}
We investigate the contribution of the local and remote atmospheric moisture fluxes to East Asia (EA) precipitation and its interannual variability during 1979-2012. We use and expand the Brubaker et al. (J Clim 6:1077-1089,1993) method, which connects the area-mean precipitation to area-mean evaporation and the horizontal moisture flux into the region. Due to its large landmass and hydrological heterogeneity, EA is divided into five sub-regions: Southeast (SE), Tibetan Plateau (TP), Central East (CE), Northwest (NW) and Northeast (NE). For each region, we first separate the contributions to precipitation of local evaporation from those of the horizontal moisture flux by calculating the precipitation recycling ratio: the fraction of precipitation over a region that originates as evaporation from the same region. Then, we separate the horizontal moisture flux across the region's boundaries by direction. We estimate the contributions of the horizontal moisture fluxes from each direction, as well as the local evaporation, to the mean precipitation and its interannual variability. We find that the major contributors to the mean precipitation are not necessarily those that contribute most to the precipitation interannual variability. Over SE, the moisture flux via the southern boundary dominates the mean precipitation and its interannual variability. Over TP, in winter and spring, the moisture flux via the western boundary dominates the mean precipitation; however, variations in local evaporation dominate the precipitation interannual variability. The western moisture flux is the dominant contributor to the mean precipitation over CE, NW and NE. However, the southern or northern moisture flux or the local evaporation dominates the precipitation interannual variability over these regions, depending on the season. Potential mechanisms associated with interannual variability in the moisture flux are identified for each region. The methods and results presented in this study can be readily applied to model simulations, to identify simulation biases in precipitation that relate to the simulated moisture supplies and transport.
\end{abstract}

Keywords Moisture transport $\cdot$ Precipitation $\cdot$ East Asia $\cdot$ Evaporation

This paper is a contribution to the special issue on East Asian Climate under Global Warming: Understanding and Projection, consisting of papers from the East Asian Climate (EAC) community and the 13th EAC International Workshop in Beijing, China on 24-25 March 2016, and coordinated by Jianping Li, Huang-Hsiung Hsu, Wei-Chyung Wang, Kyung-Ja Ha, Tim Li, and Akio Kitoh.

Liang Guo

l.guo@ reading.ac.uk

1 National Centre for Atmospheric Science, Department of Meteorology, University of Reading, P.O. Box 243, Reading RG6 6BB, United Kingdom

2 Department of Meteorology, University of Reading, P.O. Box 243, Reading RG6 6BB, United Kingdom

3 Center for Space and Habitability, University of Bern, Gesellschaftsstrasse 6, 3012 Bern, Switzerland

\section{Introduction}

East Asia (EA), especially China, spans several regions. This leads to a remarkable gradient in the annual total precipitation, from less than $25 \mathrm{~mm}$ in the remote northwest to more than $2000 \mathrm{~mm}$ in the southeast (Zhai et al. 2005). Precipitation variations over EA are predominantly determined by the EA summer monsoon (EASM) and winter monsoon (EAWM), together with the effects of topography (Domroes and Peng 1988).

To understand and forecast the variations in EA precipitation, it is essential to understand its moisture supply. Previous studies have addressed this topic using two main approaches: the hydrological approach and the meteorological approach. The hydrological approach emphasises 
finding the sources of moisture for EA precipitation. Wei et al. (2012) used a back-trajectory method to find that the moisture sources for Yangtze River Valley precipitation are mainly from land. Zhang et al. (2016) studied moisture sources for the Tibetan Plateau (TP) with the Water Accounting Model (WAM). They found that moisture evaporated from inside the region contributes about $18 \%$ of the total precipitation. Zhao et al. (2016a) studied the moisture sources for ten major river basins over China from 1980 to 2010. They found that precipitation over south and east China is mainly attributable to oceanic moisture sources, while the precipitation over northwest China is more attributable to terrestrial sources. As mentioned by Gimeno et al. (2012), methods used to estimate sources of precipitation range from analytic methods (e.g., Brubaker et al. 1993; Eltahir and Bras 1996; Burde and Zangvil 2001; Savenije 1995) to more sophisticated numerical methods (including Lagrangian and Eulerian methods) (e.g., Bosilovich and Schubert 2002; Dirmeyer and Brubaker 1999; Stohl and James 2004; de Leeuw et al. 2017), to observed physical tracers (e.g., Gat and Garmi 1970).

The meteorological approach, on the other hand, emphasises finding the pathways of moisture transport and their connections to EA precipitation. This approach is useful to connect anomalous moisture transport to variations in EA precipitation. Zhou and Yu (2005) linked the anomalous moisture transport over the Yangtze River Valley to a southwestward extension of the western Pacific subtropical high (WPSH) and a southward shift of the upper tropospheric EA jet stream. Li and Zhou (2012) found that the summer moisture transport anomaly over EA couples with different phases of the El Niño-Southern Oscillation (ENSO) in a quasi-4-year cycle, with two distinct patterns linked to an El Niño developing episode and an El Niño-to-La Niña transitional episode, separately. Feng and Zhou (2012) found that the interannual variability of summer precipitation over the TP is dominated by an anomalous circulation over northern India and the Bay of Bengal.

These two approaches analyse the relationships between EA precipitation and moisture transport on different temporal scales. Most of the hydrological studies focus on climatological relationships, while most of the meteorological studies focus on variability. Except for those aforementioned studies focusing on the interannual scale, other studies have investigated the role of moisture fluxes for extreme events (Sun and Wang 2013; Zhao et al. 2016b; Chen and Xu 2015; Huang and Cui 2015) and for long-term climate change ( $\mathrm{Li}$ et al. 2011). The classification of approaches here is based on the subject under investigation, i.e., either the sinks and sources of moisture or the influence of atmospheric processes. This differs from the conventional classification into Lagrangian and Eulerian methods. These two classifications are not completely interchangeable. Both Lagrangian and
Eulerian methods can be used to examine either the sinks and sources of moisture or the influence of atmospheric processes (e.g., Bosilovich and Schubert 2002; van der Ent et al. 2010; de Leeuw et al. 2017).

Although not explicitly analysing the relationship between EA precipitation and moisture transport, previous studies have investigated EA precipitation anomalies and their connection with variability in atmospheric circulation. In the winter, variations in EA precipitation are dominated by the EAWM, which is linked to the Arctic Oscillation (AO) and the intensity of the Siberian High (Gong and Ho 2002; Gong et al. 2001; Wu et al. 2010). Gong and Ho (2002) showed that the decrease in precipitation over mid- to high-latitude EA is correlated with a stronger Siberian High in boreal winter. Gong et al. (2001) showed that the AO plays an important role in Siberian High variability. However, showing similar connections between the EA winter precipitation and the AO or Siberian High, Wu and Wang (2002) argued that the impacts of the AO and Siberian High on EA winter precipitation are independent, with the AO dominant northward of $35^{\circ} \mathrm{N}$, and the Siberian High influential occurring primarily southward of $50^{\circ} \mathrm{N}$. Wang et al. (2000) showed that precipitation variability over southern China in winter is linked to ENSO. During El Niño in the eastern Pacific, an anomalous low-level anticyclone in the western North Pacific weakens the EAWM and increases precipitation over southern China. In the summer, precipitation interannual variability is also dominated by ENSO (Huang and Wu 1989; Wang et al. 2003; Xie et al. 2009). However, without ENSO SST anomalies over the eastern Pacific in summer, the anomalous low-level anticyclone over EA is maintained instead by local SST anomalies from both the western North Pacific and the tropical Indian Ocean. The location of this anomalous anticyclone determines the intensity of the EASM and the distribution of the precipitation over EA (Huang and Wu 1989).

The strength of coupling between local evaporation and precipitation is sensitive to soil moisture (Seneviratne et al. 2010; Koster et al. 2004). The strongest evaporation-precipitation coupling tends to occur over the transitional zones between wet and dry regions (Koster et al. 2004). In wet conditions, evaporation is not controlled by soil moisture; instead, it is controlled by the surface energy budget. In dry conditions, evaporation is strongly controlled by soil moisture, but its magnitude and variability are too small to impact precipitation. Consistent with these global studies, over EA, Wei et al. (2012) and Hua et al. (2017) found that in southeast China (a wet region), local evaporation has a weak impact on precipitation. Strong impacts of local evaporation, however, are found over mountainous regions, such as the Himalayas (van der Ent et al. 2010; Hua et al. 2017). van der Ent et al. (2010) suggested that this is mainly due to topography that confines local evaporation within the region. Furthermore, previous 
studies (Seneviratne et al. 2010; Findell et al. 2011; Goessling and Reick 2011; Guillod et al. 2014; Taylor et al. 2012; Schär et al. 1999) also show that evaporation-precipitation coupling on smaller temporal and spatial scales is sensitive to boundarylayer stability, which is referred to as local coupling or indirect feedback.

One issue that has been given less attention is whether the main source of atmospheric water vapour for a region's mean precipitation is also the major contributor to the region's precipitation variability. Existing studies on this issue show inconsistent results over EA. Keys et al. (2014) showed that the variation of precipitation over northern China is controlled by variability in evaporation from the same source region. Chen and Xu (2015), on the other hand, showed that, over the Sichuan Basin, moisture originating from the TP, Indian Peninsula, Bay of Bengal and the Arabian Sea makes considerable contributions to heavy precipitation events; however, these areas are less important to the precipitation climatology. To address this issue, we apply both hydrological and meteorological approaches in this study to investigate the relationship between moisture transport and regional precipitation on climatological and interannual scales. First, we quantify the contributions (locally evaporated moisture and horizontal moisture fluxes into the region) to the mean regional precipitation over EA. Secondly, we identify the main contributors of the horizontal moisture fluxes (by direction) to precipitation interannual variability.

Section 2 introduces the data and methods used. Section 3 examines links between the mean regional precipitation and the mean moisture transport. Section 4 investigates relationships between the regional EA precipitation and the moisture influx at interannual scales, and explores the potential mechanisms associated with these variations. Section 5 discusses the limitations of the method and data. Section 6 summarises our results.

\section{Data and methods}

\subsection{Precipitation recycling ratio and advected moisture contribution}

The precipitation recycling ratio is the fraction of precipitation over a region that originates as evaporation from the same region. Previous studies have estimated the recycling ratio in various regions with various methods (Eltahir and Bras 1996; Brubaker et al. 1993; Trenberth 1999; Savenije 1995; Schär et al. 1999; Burde and Zangvil 2001; van der Ent et al. 2010; Gimeno et al. 2012). In this study, we use the two-dimensional precipitation recycling ratio from Brubaker et al. (1993) (B1993, henceforth):
$\rho=\frac{E A}{E A+2 F^{i n}}$,

where $\rho$ is the precipitation recycling ratio within a region (unitless); $E$ is the area-mean evaporation in the region $\left(\mathrm{kg} \mathrm{m}^{-2} \mathrm{~s}^{-1}\right) ; F^{\text {in }}$ is the horizontal moisture flux into the region $\left(\mathrm{kg} \mathrm{s}^{-1}\right)$; and $A$ is the size of the region $\left(\mathrm{m}^{2}\right)$.

Equation 1 is derived from the mass conservation of atmospheric water vapour based on three assumptions. The simplicity of Eq. 1 makes it easy to apply. However, the three assumptions inevitably introduce limitations and uncertainty in its application. We will discuss the implications of these limitations later in Sect. 5. To assist our discussion, we describe these assumptions here; more information can be found in B1993 and Burde and Zangvil (2001). The vertically integrated mass conservation of atmospheric water vapour for a unit area is

$\frac{\partial Q}{\partial t}=-\left(\frac{\partial F_{u}}{\partial x}+\frac{\partial F_{v}}{\partial y}\right)+E-P$,

where $Q$ is the vertically integrated atmospheric water vapour $\left(\mathrm{kg} \mathrm{m}^{-2}\right) ; F_{u}$ and $F_{v}$ are the vertically integrated horizontal moisture fluxes $(\mathrm{kg} \mathrm{m} \mathrm{s})$; and $E$ and $P$ are the evaporation and precipitation $\left(\mathrm{kg} \mathrm{m}^{-2} \mathrm{~s}^{-1}\right)$, respectively.

The first assumption is that at sufficiently long timescales (e.g., monthly), the change in storage of atmospheric water vapour is small compared to the moisture flux, i.e., $\frac{\partial Q}{\partial t}=0$. Equation 2 can then be written as

$\left(\frac{\partial F_{u}}{\partial x}+\frac{\partial F_{v}}{\partial y}\right)=E-P$

which shows the hydrological balance between the horizontal moisture flux divergence, evaporation and precipitation. This assumption has been relaxed in later studies, e.g., Dominguez et al. (2006).

The second assumption is that the atmosphere is wellmixed in the direction perpendicular to the atmospheric flow, such that precipitated water consists of locally evaporated (i.e., recycled) and advected water in equal proportion to the ratio of locally evaporated and advected moisture in the atmosphere within the region:

$\frac{P_{a}}{P}=\frac{Q_{a}}{Q}$ or $\frac{P_{e}}{P}=\frac{Q_{e}}{Q}$,

where $P_{a}$ is the component of precipitation arising from advected moisture and $P_{e}$ is the component of precipitation arising from local evaporation $\left(P_{a}+P_{e}=P\right) ; Q_{a}$ is the component of atmospheric moisture arising from advected moisture and $Q_{e}$ is the component of atmospheric moisture arising from local evaporation $\left(Q_{a}+Q_{e}=Q\right)$. Eq. 4 is widely used and fundamental for studies of the precipitation recycling ratio (Burde and Zangvil 2001). It allows 
mass conservation to be applied to the advected portion of precipitation,

$\left(\frac{\partial F_{u}^{a}}{\partial x}+\frac{\partial F_{v}^{a}}{\partial y}\right)=-P_{a}$,

where $F_{u}^{a}$ and $F_{v}^{a}$ are the vertically integrated horizontal moisture flux of advected moisture.

The third assumption is that $E, P$ and $P_{a}$ are constant within the region under study, such that the area-mean evaporation, area-mean precipitation and its partition into evaporated and advected components are characteristic of all points within the region. Applying the third assumption and the Gauss divergence theorem, the area-integrals of Eqs. 3 and 5 over a region with area of $A\left(\mathrm{~m}^{2}\right)$ can be simplified to

$\left.\nabla \cdot F\right|_{A}=F^{\text {out }}-F^{\text {in }}=(E-P) A$,

$\left.\nabla \cdot F_{a}\right|_{A}=F_{a}^{\text {out }}-F^{\text {in }}=-P_{a} A$,

where $\left.\nabla \cdot F\right|_{A}$ is the divergence of horizontal moisture flux and $\left.\nabla \cdot F_{a}\right|_{A}$ is the divergence of horizontal flux of advected moisture; $F^{\text {out }}$ is the horizontal moisture flux out of the region; and $F_{a}^{\text {out }}$ is the horizontal flux of advected moisture out of the region.

As shown in Eqs. 6 and 7, $F^{\text {out }}$ and $F_{a}^{\text {out }}$ are linearly related to $F^{\text {in }}$. Therefore, the mean horizontal moisture fluxes can be represented as the arithmetic mean of the influx and outflux:

$\bar{F}=\frac{F^{\text {in }}+F^{\text {out }}}{2}=F^{\text {in }}+\frac{(E-P) A}{2}$,

$\bar{F}_{a}=\frac{F^{\text {in }}+F_{a}^{\text {out }}}{2}=F^{\text {in }}-\frac{P_{a} A}{2}$.

By assuming the proportions of advected moisture and evaporated moisture in a region change linearly from upstream to downstream, the mean horizontal moisture fluxes are also in equal proportion to the ratio of advected and evaporated precipitation similar to Eq. 4, i.e., $\frac{P_{a}}{P}=\frac{\bar{F}_{a}}{\bar{F}}$. Therefore, B1993's precipitation recycling ratio (Eq. 1) is gained by applying Eqs. 8 and 9 to $\frac{P_{a}}{P}=\frac{\bar{F}_{a}}{\bar{F}}$. Note that, by assuming that the proportions of advected moisture and evaporated moisture remain constant within a region, Schär et al. (1999) derived another form of $\rho$. In Schär et al. (1999)'s calculation, the weight given to the moisture influx in the denominator is smaller. More discussion about the limitations and validity of our adaptation of the B1993 method can be found in Sect. 5.

Considering two extreme cases can help to understand this framework. In one case, the region under consideration is the entire globe. In this case, there is no horizontal moisture flux $(I=0)$. Therefore, $\rho=1$ and the moisture for the global mean precipitation comes entirely from the global mean evaporation. In another case, the region under consideration is a single point. In this case, any moisture evaporated from this point is immediately exported elsewhere by the atmospheric circulation. Therefore, the portion of evaporation that contributes to precipitation at this point is zero $(E A=0)$, and $\rho=0$.

The fraction of precipitated moisture that is advected horizontally into the region can also be calculated as $1-\rho$ according to Eq. 1,

$\alpha=\frac{P_{a}}{P}=1-\rho=\frac{2 F^{i n}}{E A+2 F^{i n}}$,

where $\alpha$ is the contribution of precipitation arising from advected moisture to total precipitation within a region. If we further divide the total moisture influx $F^{\text {in }}$ according to the direction of the moisture transport, $\alpha$ term can be divided into,

$\alpha_{W}=\frac{2 F_{W}^{i n}}{E A+2 F^{i n}} ; \alpha_{E}=\frac{2 F_{E}^{i n}}{E A+2 F^{i n}} ;$

$\alpha_{N}=\frac{2 F_{N}^{i n}}{E A+2 F^{i n}} ; \alpha_{S}=\frac{2 F_{S}^{i n}}{E A+2 F^{i n}}$,

and $\alpha=\alpha_{W}+\alpha_{E}+\alpha_{N}+\alpha_{S}$,

where $F_{W}^{i n}$ is the horizontal moisture influx through the western boundary; $\alpha_{W}$ is the contribution of precipitation arising from advected moisture through the western boundary. Similar subscripts are assigned to represent directions of east $(E)$, north $(N)$ and south $(S)$ in Eq. 11. Incorporating Eqs. 11 into 10, we have:

$\rho+\alpha_{W}+\alpha_{E}+\alpha_{N}+\alpha_{S}=1$.

In the following sections, each term in Eq. 13 will be calculated and discussed.

\subsection{Coefficient of multi-determination}

The coefficient of multi-determination $\left(R^{2}\right)$ is defined as the square of the coefficient of multiple correlation $(R) . R$ is the correlation between the dependent variable (precipitation $P$ in our case) and the best explanation that can be computed linearly from predictive variables (horizontal moisture influxes $F_{x}^{i n}$ and local evaporation $E$ in our case, where $x$ refers to the direction, i.e., W, E, N and S.). A higher value of $R^{2}$ indicates a better explanation of the dependent variable by the independent variables, with 1 indicating that variations of the dependant variable are fully explained by the linear combination of the independent variables. $R^{2}$ can be computed using:

$R^{2}=\mathbf{c}^{T} R_{x x}^{-1} \mathbf{c}$,

where the vector $\mathbf{c}=\left(r_{F_{W}^{i n} P}, r_{F_{E}^{i n} P}, r_{F_{N}^{i n} P}, r_{F_{S}^{i n}}, r_{E P}\right)^{T}$ consists of correlation coefficients between the monthly horizontal moisture influxes $F_{x}^{i n}$, local evaporation $E$ and the 
monthly regional precipitation $P$. The matrix $R_{x x}$ is the intercorrelations between $F_{x}^{\text {in }}$ and $E$ :

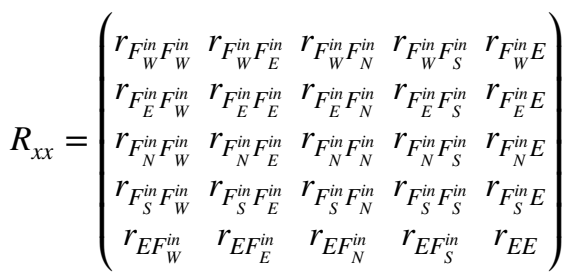

Further, $\mathbf{c}^{T}$ is the transpose of $\mathbf{c}$, and $R_{x x}^{-1}$ is the inverse of matrix $R_{x x}$.

\subsection{Data}

The ERA-Interim re-analysis dataset during 1979-2012 (Berrisford et al. 2011; Dee et al. 2011) from the European Centre for Medium-Range Weather Forecasts is used in this study. Variables used include precipitation, evaporation, mean sea-level pressure and vertically integrated moisture flux. All variables are monthly means and gridded onto a 512 longitude $\times 256$ latitude regular grid with a resolution of approximately $0.7^{\circ} \times 0.7^{\circ}$. Trenberth et al. (2011) pointed out that the global hydrological budget is not closed in many reanalyses due to the analysis increment applied by the data assimilation scheme. Our choice of ERA-Interim is justified by the fact that the residual in the global hydrological budget is the smallest among reanalyses, according to Trenberth et al. (2011). ERA-Interim shows the highest fidelity among reanalyses in terms of reproducing the EA monsoon precipitation climatology and its interannual variability (Lin et al. 2014). When comparing the evaporation in reanalyses to observations over China ( $\mathrm{Su}$ et al. 2015), ERA-Interim produced a reasonable estimate in both the spatial pattern and interannual variations.

We also use the Hadley Centre Sea Ice and Sea Surface Temperature monthly dataset from 1979 to 2012 on a $1^{\circ} \times 1^{\circ}$ global grid (Rayner et al. 2003) and the Global Precipitation Climatology Project v2.3 monthly dataset from 1979 to 2012 on a $2.5^{\circ} \times 2.5^{\circ}$ global grid (Adler et al. 2003). The atmospheric teleconnection indices (North Atlantic Oscillation, i.e., NAO and AO) and Niño3.4 index are downloaded from the National Oceanic and Atmospheric Administration Climate Prediction Center (http://www.cpc.noaa.gov/products/ precip/CWlink/MJO/climwx.shtml).

\subsection{Dividing the study regions}

EA crosses several climatic zones. To study its hydrological cycle, EA is first subjectively divided into smaller regions that are relatively homogeneous in terms of their hydrological features. Generally, smaller regions will be more homogeneous. However, to keep the number of regions manageable, we identify five regions according to $P-E$ (precipitation minus evaporation) and orography. Previous studies have divided EA into hydrological regions based on different methods: on the observed precipitation and its leading patterns analysed by the Empirical Orthogonal Functions (EOF) (Ma et al. 2015; Zhu 2003); on the standardised precipitation index (SPI) ( $\mathrm{Li}$ et al. 2015); and on geographical features, such as basins and river catchments (Zhao et al. 2016a). However, EOF analysis of precipitation over-emphasises the eastern coastal areas where the total precipitation and its variation are largest; the SPI does not reflect differences in the actual precipitation amount; and although the hydrological features over river catchments are homogenous, the areas of these catchments are too small to apply this method to the entire EA landmass.

Figure 1 shows the annual mean $P-E$ in ERA-Interim for 1979-2012. $P$ exceeds $E$ over southern China, the eastern part of TP and northeastern China. $P$ and $E$ are comparable over northwestern China. The regional boundaries also follow the orography (Fig. 1). Region 1 covers southeastern China; region 2 covers the TP; region 3 covers central eastern China, including both the northern China Plain and the Northeast Plain; region 4 covers northwestern China, including the Loess Plateau, the Inner Mongolia Plateau and the deserts of northwestern China; region
Fig. 1 (Left) Annual mean precipitation minus evaporation $(P-E)$, calculated using the ERA-Interim re-analysis during 1979-2012, units: m/year; (right) Topography over the EA landmass, units: $\mathrm{m}$. Boxes 1 to 5 in (left) indicate sub-regions over EA
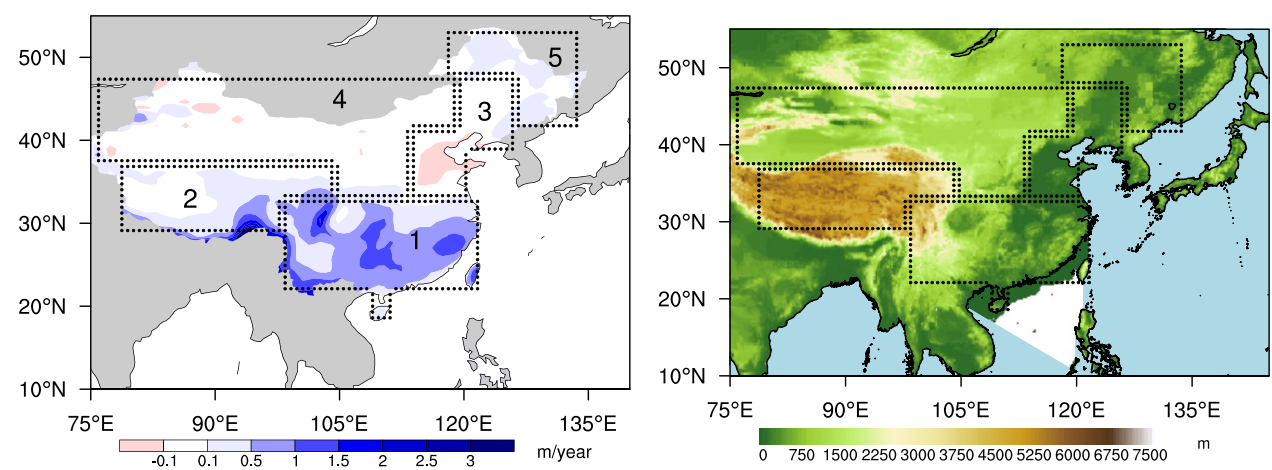
5 covers northeast China including the Great and Lesser Khingan and Paektu Mountain ranges.

\section{Moisture fluxes contributing to mean precipitation}

\subsection{Seasonal cycle of moisture budget over East Asia}

The mean seasonal cycles of the hydrological components (i.e., $P, E$ and the convergence of the vertically integrated moisture flux) for each region are shown in Fig. 2. For all five regions, the seasonal cycles show a single peak in boreal summer. Over region $1, P$ exceeds $E$ from March to September, indicating that this is a wet region. The moisture flux convergence is large over this region. Compared with region 1 , the other regions experience drier winters with $P<1 \mathrm{~mm} /$ day from November to March. There are some similarities between regions 3 and 5, both of which show low precipitation except during the EASM season. The moisture flux convergence shows its maximum over both regions in July. The impact of the EASM over region 4 is much smaller compared to the other regions, as the areamean horizontal moisture flux convergence is nearly zero all

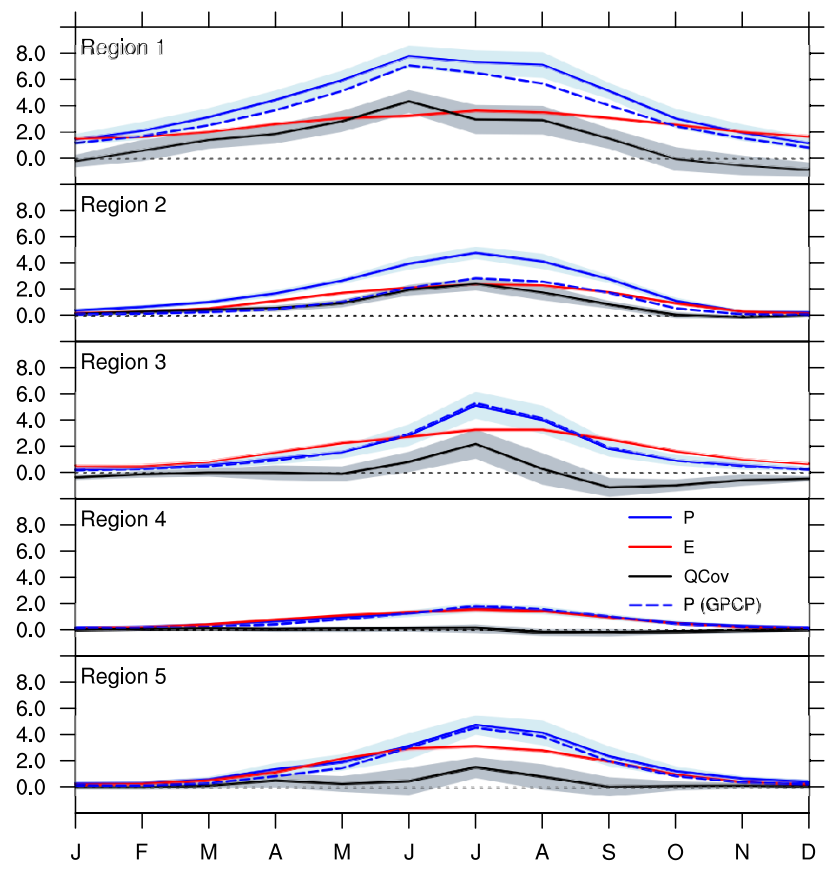

Fig. 2 Mean seasonal cycles of precipitation $(P)$, evaporation $(E)$ and the convergence of the vertically integrated moisture flux (QCov) using the ERA-Interim re-analysis during 1979-2012 for five regions defined in Fig. 1. Units: mm/day. The pale envelope indicates the $\pm 1 \sigma$ range of interannual variability about the mean. The GPCP precipitation during 1979-2012 is shown as the blue dashed lines year round; $E$ and $P$ balance out each other. However, as we will show in the following sections, $P$ over region 4 relies largely on the horizontal atmospheric moisture transport.

\subsection{Precipitation recycling ratio over East Asia}

The mean annual $\rho$ for all regions during 1979-2012 is calculated using Eq. 1 and used in Fig. 3 as input to schematic diagrams that show the regional hydrological cycle. All components shown in Fig. 3 are standardised by dividing by the annual mean precipitation then multiplying by 100 . By doing so, the relative importance of different hydrological components in the five regions can be compared. Note that direct comparison between regions is difficult as $\rho$ is affected by the size and shape of each region. Nevertheless, Fig. 3 shows that $\rho$ is highest over TP (region 2, 20.83\%), followed by region 4 (northwestern, $14.77 \%$ ) and region 1 (southeastern, 13.63\%). The higher $\rho$ over the TP (region 2) is consistent with previous studies (van der Ent et al. 2010; Zhang et al. 2016). In hydrology, a related term to $\rho$ is also used-the evaporation recycling ratio, which describes the proportion of evaporated water that returns as precipitation in the same region. This ratio can be easily derived using $\rho$ and the standardised $E$ from Fig. 3. The evaporation recycling ratio over regions 1 and 2 (23 and 36\%) is much higher than that over regions 3,4 and 5 (8, 15 and $13 \%$, respectively). It is interesting to see that although $\rho$ is comparable between regions 1 and 4, the evaporation recycling ratio over region 4 is smaller. This indicates that $P$ over region 4 is small and that a larger fraction of the evaporated water is exported. From Fig. 3, we can also derive the conversion ratio of $F_{\text {in }}$ to $P$ by calculating the $\frac{P_{a}}{F^{i n}}$. The conversion ratio over regions 1 and 2 (43 and 62\%) is higher than regions 3, 4 and 5 (14, 26 and $22 \%$ respectively).

The mean seasonal cycle of $\rho$ (Fig. 4) shows that the maximum $\rho$ does not occur in summer when the EASM prevails and precipitation is strongest (grey bars). According to Eq. 1, $\rho$ is proportional to $E$ but inversely proportional to $F_{\text {in }}$ (blue bars), which peaks during summer over all five regions due to the EASM, especially over eastern China (regions 1, 3 and 5). Therefore, over these regions, $\rho$ is smaller during the EASM compared to spring and autumn. As shown in Fig. 4, over region 1 , the seasonal variation of $F^{i n}$ outweighs that of $E$, thus $F^{\text {in }}$ controls $\rho$. But in other regions, the seasonal variation of $E$ is larger than that of $F^{\text {in }}$, so $E$ controls $\rho$. These distinct regimes show the different constraints on the seasonal variation of $\rho$ between region 1 and other regions. This is also manifested by the correlation coefficients between $\rho$ and $E$ and $F^{i n}\left(r(\rho, E)\right.$ and $\left.r\left(\rho, F^{i n}\right)\right)$ shown in Figure 4. $\rho$ has a significant negative correlation with $F^{\text {in }}$ over region 1 , while $\rho$ is significantly positively correlated with $E$ over other regions. 
Fig. 3 Schematics of the mean annual water cycle over five regions. The top-left panel is a key. The $F^{i n}$ is the horizontal moisture flux into the region; $P_{a}$ is the component of precipitation arising from advected moisture; $F^{o u t}$ is the horizontal flux of moisture advected out of the region; $\rho$ is the precipitation recycling ratio, which represents the amount of locally evaporated moisture that contributes to precipitation within the region; $F_{e}^{\text {out }}$ is horizontal flux of locally evaporated moisture advected out of the region. runoff is calculated as a residual of precipitation minus evaporation. All variables are calculated using the ERA-Interim re-analysis during 1979-2012. All variables are standardised by dividing by the annual mean area-integrated precipitation (shown in the parentheses of each panel), then multiplying by 100
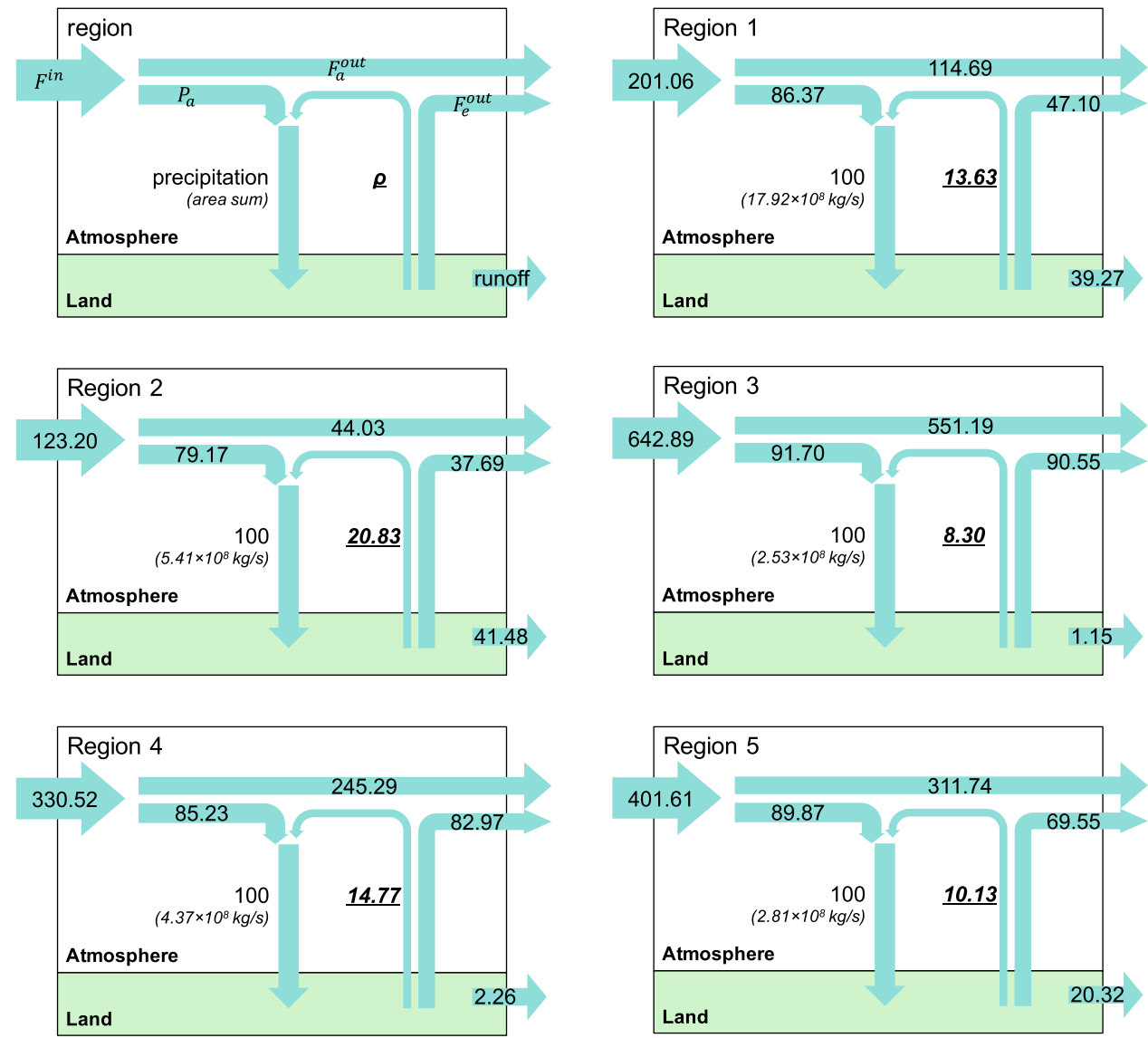

\subsection{Contribution of advected moisture transport}

By calculating $\rho$, we know that $F^{\text {in }}$ accounts for between 80 and $92 \%$ of the mean precipitation in these regions. To investigate from which directions the precipitation receives its moisture supply, we calculate these contributions from each direction using Eq. 11. The separation of the boundaries of each region according to direction is shown in Fig. 5a. The percentage contributions from all directions including the local evaporation are shown in Fig. 5b-f, of which the sum must be 1 according to Eq. 13 . Figure $5 \mathrm{~g}-\mathrm{k}$ shows the same contribution but to the actual monthly mean precipitation for 1979-2012.

The main contributions to the mean precipitation in each region are also summarised by season and shown in the upper part of Table 1. The moisture influx via the southern boundary dominates the mean precipitation over region 1 throughout the year. In particular, it provides over $60 \%$ of the moisture for precipitation in MAM and JJA. Although the southern moisture influx is a major contributor over region 2 in JJA and SON, it is not as dominant in other seasons as over region 1. Instead, the moisture influx via the western boundary dominates in DJF and MAM. Over regions 3, 4 and 5, the southern moisture influx shows a signature of the EASM during JJA, but the western moisture influx dominates throughout the year. This result is consistent with previous studies that suggested that the moisture flux from the west is a major contributor for precipitation over EA (van der Ent et al. 2010; Zhao et al. 2016a; Wei et al. 2012; Sun and Wang 2014; Drumond et al. 2011).

\section{Moisture influx variations contributing to East Asian precipitation interannual variability}

To investigate the contributions of interannual variability in moisture influxes from each of five directions (evaporation is also included as the fifth direction) to the interannual variability of precipitation, we calculate the correlation coefficients between the moisture influx and precipitation using seasonal mean values during 1979-2012 (Table 1). Comparing the mean and interannual variability in Table 1 , we find that the major contributors of moisture influxes to the mean precipitation are not necessarily the major contributors to the precipitation interannual variability. Over region 1 , the moisture influx via the southern boundary dominates the precipitation on both temporal scales. Over region 2, in DJF and MAM, the moisture flux via the western boundary 
Fig. 4 Normalised seasonal cycles of the precipitation recycling ratio $(\rho)$, the vertically and evaporation $(E)$ calculated from ERA-Interim re-analysis five regions. Each variable is normalised by its January value. Correlation coefficients between $\rho$ and $F^{i n}, r\left(\rho, F^{i n}\right)$, as well as correlation coefficients between $\rho$ and $E, r(\rho, E)$, are shown below the key. Correlation coefficients are calculated using area-mean monthly values during 1979-2012. Correlation coefficients that are significant at the $90 \%$ confidence level are set in boldface integrated moisture influx $\left(F^{i n}\right)$ during 1979-2012 for the
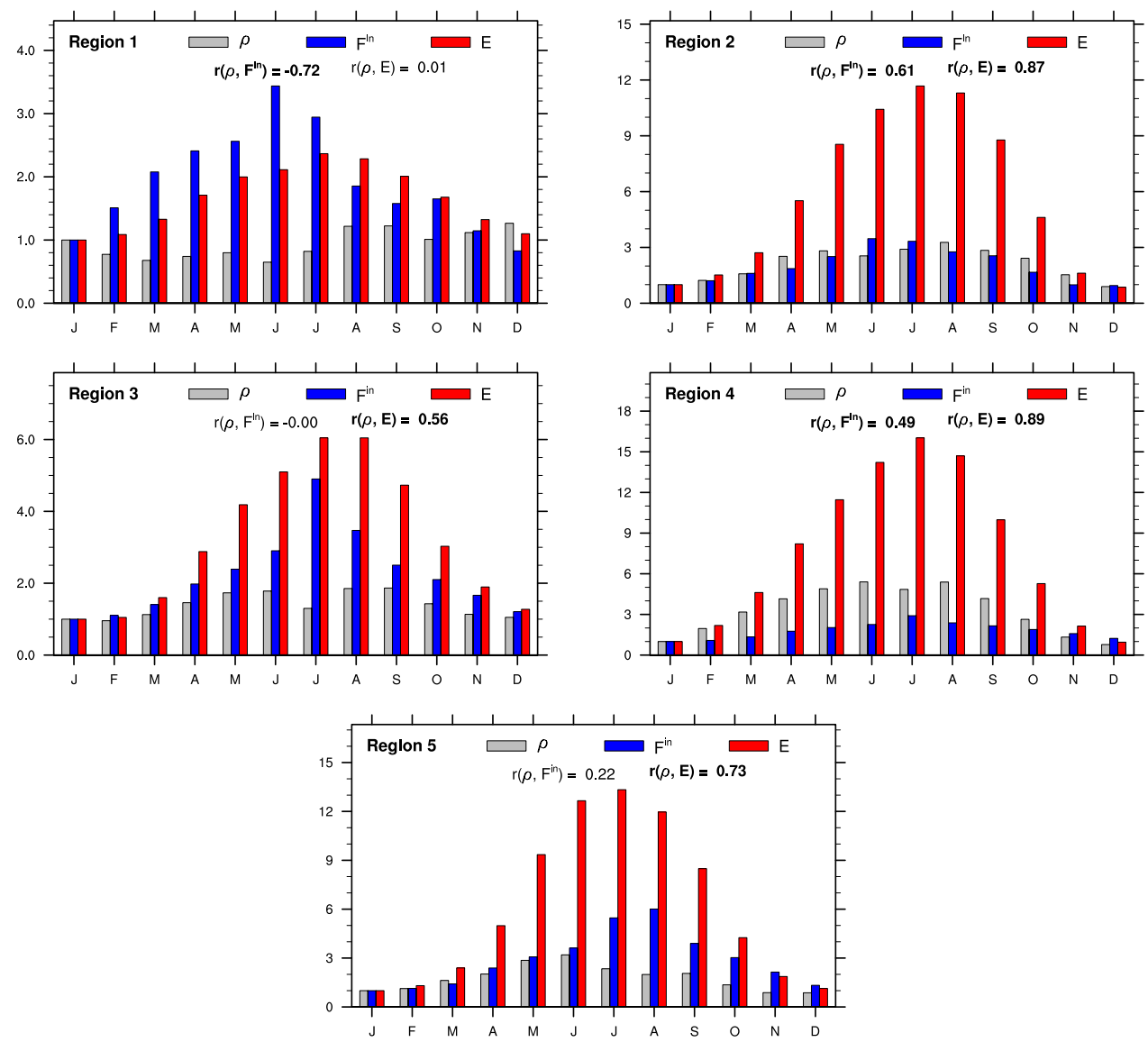

dominates the mean precipitation, however, the local evaporation dominates the precipitation interannual variability. The western moisture influx is the dominant contributor to the mean precipitation over regions 3, 4 and 5. However, the southern or northern moisture flux or the local evaporation dominates the precipitation interannual variability over these regions depending on the season. With this comparison, we learn that the moisture influxes from some directions are large but stable, while the moisture influxes from other directions are smaller but become important controlling factors for the interannual variability. Identifying the potential mechanisms behind these variations of moisture influxes can improve our ability to understand and predict the variations of EA precipitation. Next, we consider these potential mechanisms for each direction in turn.

\subsection{Western boundaries}

Moisture influxes via the western boundaries of region 4 in DJF and SON and of region 5 in DJF have significant positive correlations with precipitation variability. Figure $6 \mathrm{a}$ shows the regression coefficients of the mean sea-level pressure (MSLP) regressed onto the western moisture influx of region 4 in DJF. Over the northern Atlantic and western Europe, the MSLP anomaly resembles the negative phase of NAO, that is, a positive MSLP anomaly at higher latitudes that weakens the Icelandic low and a negative MSLP anomaly at lower latitudes that weakens the Azores High. As a result, the low-level westerlies shift to the south, along with the jet stream and storm track, which changes the flow of atmospheric moisture to China via the western boundary of region 4. As shown in Fig. 6b, there are stronger moisture fluxes across the Mediterranean Sea, the Black Sea and the Caspian Sea before the flow reaches the western boundary of region 4 . We hypothesise that the increased evaporation from these seas strengthens the moisture transport to region 4. This relationship can also be illustrated by the significant negative correlation between the NAO index and the western influx of region 4 in DJF (Table 2).

Regression coefficients are weaker for MSLP and the moisture influx with region 4 in SON and region 5 in DJF on their western boundaries (not shown). This may be due to the NAO being weaker during SON and region 5 being further east, away from the NAO centres of action and the influence of the Atlantic jet stream. The correlation coefficients between the NAO index and these moisture influxes are not significant, but remain negative. 
(a)

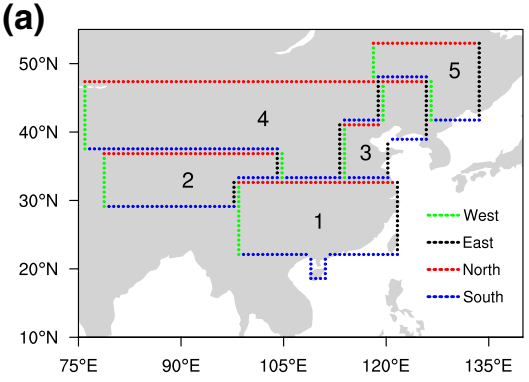

(d) 1

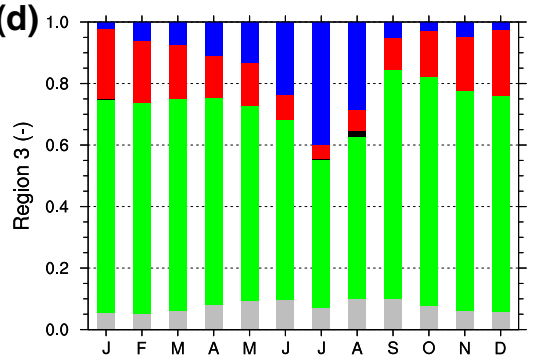

(b)

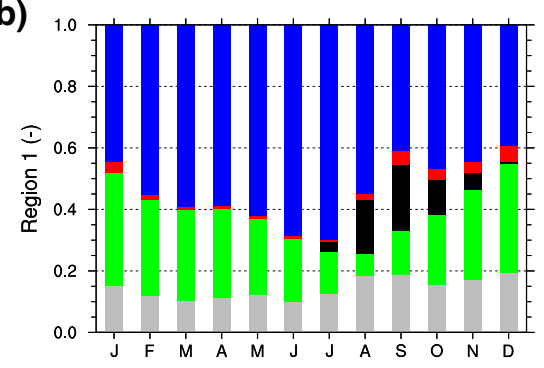

(e)

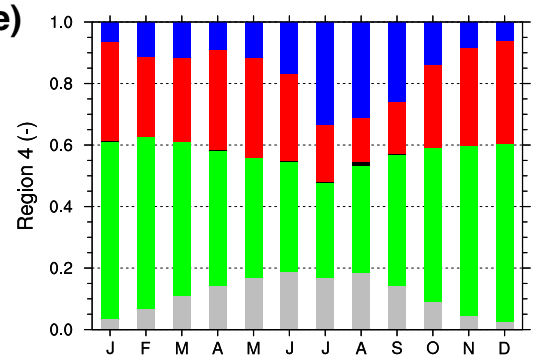

(g)

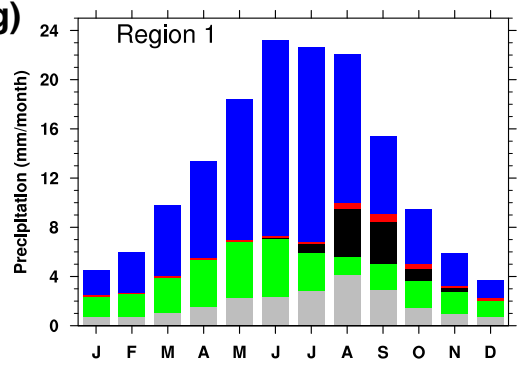

(j)

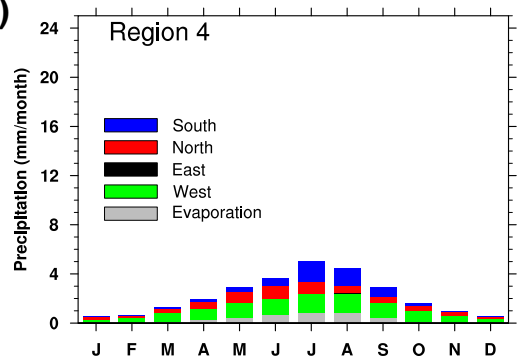

(c)

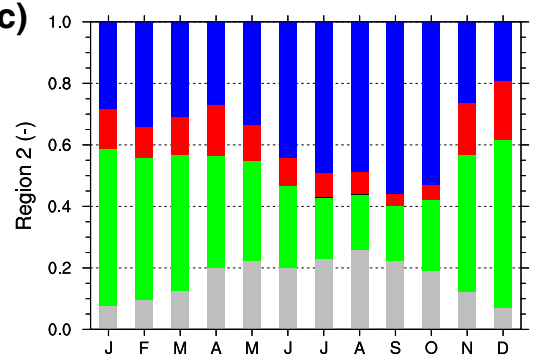

(f)

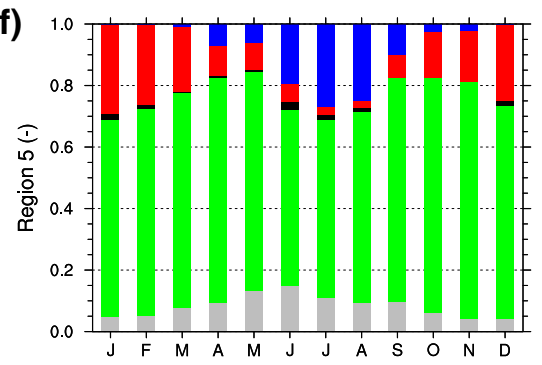

(h)

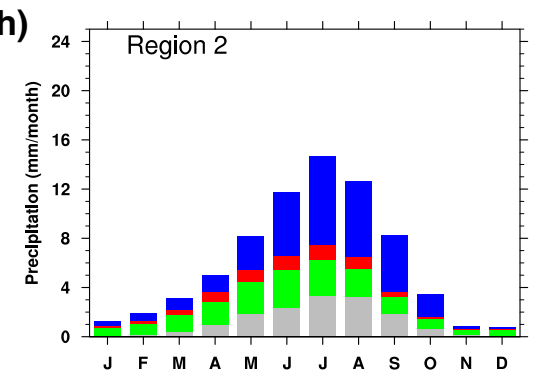

(k)

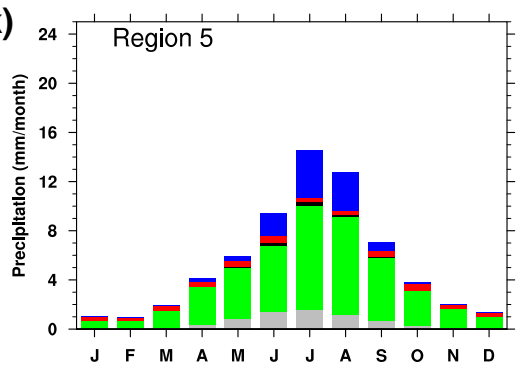

Fig. 5 a Divisions of each regions boundaries. For each region, the boundary is divided into west (green), east (black), north (red) and south (blue). b-f The percentage contributions to precipitation from the moisture influxes from different directions, as well as from the local evaporation $(\rho)$, which is in gray. $\mathbf{g}-\mathbf{k}$ The mean seasonal cycles of precipitation in the five regions calculated from the ERA-Interim re-analysis during 1979-2012, units: $\mathrm{mm} / \mathrm{month}$. The precipitation is separated into colours according to the moisture contributions from each section of the boundary

\subsection{Northern boundaries}

Moisture influxes via the northern boundaries of region 1 in DJF and of region 5 in DJF and JJA have significant negative correlations with precipitation variability. Over regions 1 and 5, in DJF, the northern moisture influx is associated with the EAWM. The advection of cool and dry air southward is associated with reduced precipitation. Figure 7 shows regression coefficients of surface pressure $\left(P_{s}\right)$ regressed onto the moisture influxes across the northern boundaries of regions 1 and 5 in DJF. For region $1, P_{s}$ shows a positive anomaly over the polar region and a negative anomaly over lower and middle latitudes, which resembles the AO negative phase. The pattern of the negative AO, especially the high pressure anomaly over Siberia $\left(40^{\circ}-60^{\circ} \mathrm{N}, 60^{\circ}-190^{\circ} \mathrm{E}\right)$ resembles the relationship between the Siberian High and EA winter precipitation discussed in Gong et al. (2001) and Gong and Ho (2002). Along the eastern flank of the Siberian 
Table 1 Major contributions to the mean precipitation (upper half) and its inter-annual variability (lower half) over the five regions

\begin{tabular}{|c|c|c|c|c|c|}
\hline & Region 1 & 2 & 3 & 4 & 5 \\
\hline \multicolumn{6}{|c|}{ Climatology } \\
\hline DJF & $\mathrm{S}, \mathrm{W}$ & $\mathrm{W}, \mathrm{S}$ & W & $\mathrm{W}, \mathrm{N}$ & W \\
\hline MAM & $\mathrm{S}$ & W,S & W & W,N & W \\
\hline JJA & $\mathrm{S}$ & $\mathrm{S}, E_{v}$ & W,S & $\mathrm{W}, \mathrm{S}$ & W,S \\
\hline SON & $\mathrm{S}, \mathrm{W}$ & $\mathrm{S}, \mathrm{W}$ & W & $\mathrm{W}, \mathrm{N}$ & W \\
\hline \multicolumn{6}{|c|}{ Inter-annual variation } \\
\hline DJF & $\mathrm{S}, \mathbf{N}$ & $E_{v}$ & $\mathrm{~S}$ & W & $\mathrm{W}^{*}, \mathbf{N}^{*}$ \\
\hline MAM & $\mathrm{S}$ & $E_{v}^{*}$ & $\mathrm{~S}, E_{v}$ & $E_{v}, \mathrm{~S}$ & $\mathrm{~S}^{*}$ \\
\hline JJA & $\boldsymbol{E}_{\boldsymbol{v}}^{*}, \mathrm{~S}^{*}$ & $\mathrm{~S}$ & $\mathrm{~S}$ & $E_{v}$ & $\mathbf{N}$ \\
\hline SON & $\mathrm{S}$ & $\mathrm{S}$ & $\mathrm{S}$ & $\mathrm{W}, \mathrm{S}, E_{v}$ & $\mathrm{~S}$ \\
\hline
\end{tabular}

According to the boundary definitions shown in the top-left panel of Fig. 5, $W$ is the western section, $E$ is the eastern section, $N$ is the northern section, $S$ is the southern section and $E_{v}$ is the local evaporation. For the mean contribution, directions are listed in order of the percentage of precipitation explained, until the total fraction explained is greater than $60 \%$. For inter-annual variation contribution, all directions with the correlation coefficients between the moisture influxes and the precipitation larger than \pm 0.5 are listed. For the regions where no value of correlation meets this threshold, the threshold is reduced to \pm 0.4 . Such cases are denoted by $*$

Bold text indicates the correlation coefficients are negative

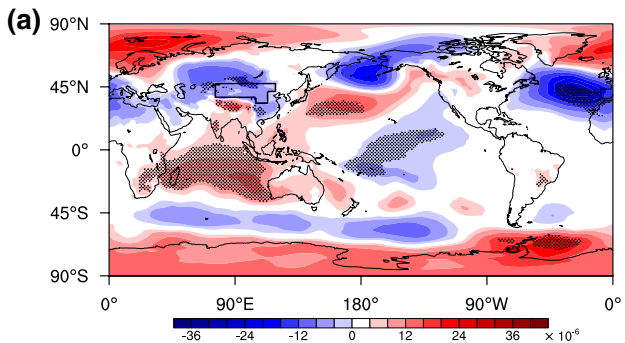

Fig. 6 a Regression coefficients of MSLP regressed onto the moisture influx across the west boundary of region 4 in DJF during 19792012. Units: $\mathrm{Pa} /(\mathrm{kg} / \mathrm{s})$. Regression coefficients that exceed the $90 \%$ confidence level are stippled. b Regression coefficients of vertically integrated moisture flux regressed onto the moisture influx across the west boundary of region 4 in DJF during 1979-2012. Units: $(\mathrm{kg} / \mathrm{m} / \mathrm{s}) /$
High, the cool and dry air is advected south, which is associated with reduced precipitation over region 1 .

Over region 5, however, the change in $P_{S}$ is of opposite sign and resembles the positive AO. Since the northern boundary of region 5 is located at $55^{\circ} \mathrm{N}$, there is no need for a large meridional wind anomaly to bring cool air across the boundary as is the case for region 1. In fact, it is during the AO positive phase, when cool air is confined to high latitudes, that the northern moisture influx has its significant impact over region 5. These impacts of the opposite patterns of the $\mathrm{AO}$ on the winter precipitation over regions 1 and 5 contradict Gong et al. (2001), but are supported by Wu and Wang (2002) who found that the impacts of the AO and the Siberian High on the EA winter precipitation are independent. The correlation coefficients between the AO index and the northern moisture influxes of regions 1 and 5 during DJF also reflect the aforementioned relationship (Table 2). The insignificant negative correlation coefficient between the AO index and the northern moisture influx of region 1 may be because the direct link is weak, thus the variations of AO and the northern moisture influx are linked via the Siberian High.

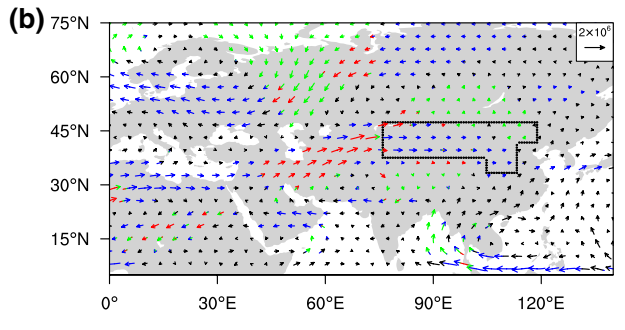

$(\mathrm{kg} / \mathrm{s})$. Colours indicate the regression coefficients are significant at the $90 \%$ confidence level: blue indicates that the regression coefficient of zonal moisture flux is significant; green indicates that the regression coefficient of meridional moisture flux is significant; red indicates that regression coefficients of both directions are significant

Table 2 Correlation coefficients between the indies (NAO, AO and Niño 3.4) and the moisture influxes over different region boundaries in corresponding seasons that are mentioned Sects. 4.1, 4.2 and 4.3

\begin{tabular}{|c|c|c|c|c|c|c|}
\hline & \multicolumn{3}{|c|}{ Western boundary } & \multicolumn{3}{|c|}{ Northern boundary } \\
\hline & r4 DJF & r5 DJF & r4 SON & & r1 DJF & r5 DJF \\
\hline \multirow[t]{3}{*}{ NAO } & -0.31 & -0.20 & -0.07 & $\mathrm{AO}$ & -0.11 & 0.37 \\
\hline & \multicolumn{6}{|c|}{ Southern boundary } \\
\hline & r1 DJF & r3 DJF & r1 MAM & r3 MAM & r4 MAM & r5 MAM \\
\hline Niño 3.4 & 0.47 & 0.26 & 0.68 & 0.54 & 0.40 & 0.14 \\
\hline
\end{tabular}

Values that exceed the $90 \%$ confidence level are set in boldface 

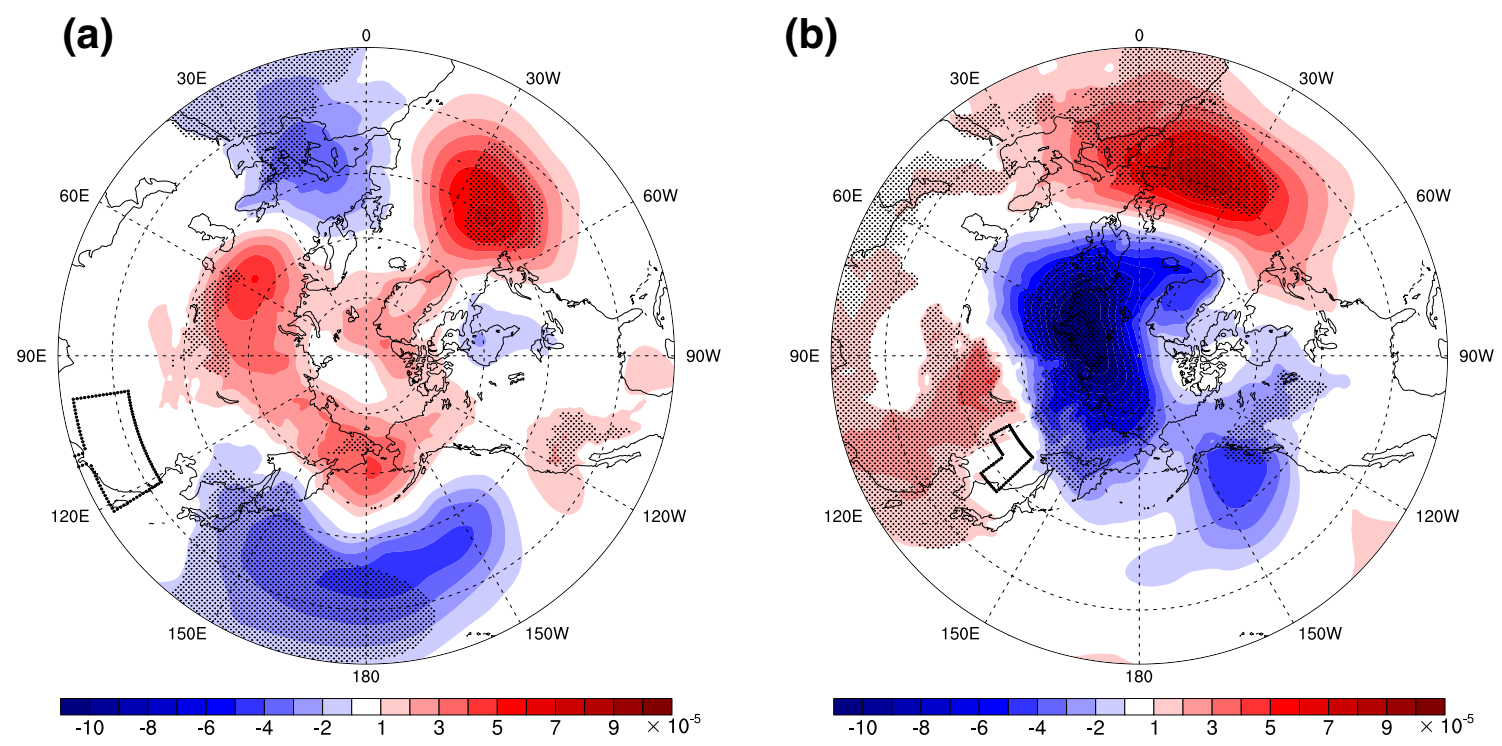

Fig. 7 Regression coefficients of $P_{s}$ regressed onto the moisture influx across the north boundaries of regions a 1 and b 5 in DJF during 19792012. Regression coefficients that exceed the $90 \%$ confidence level are stippled. Units: $\mathrm{Pa} /(\mathrm{kg} / \mathrm{s})$

\subsection{Southern boundaries}

In DJF, the moisture influxes via the southern boundaries of regions 1 and 3 have significant correlations with precipitation variability. In MAM, the southern moisture influxes of regions 1, 3, 4 and 5 have significant correlations with precipitation variability. The regression coefficients of SST regressed onto the southern moisture influxes over these regions are shown in Fig. 8. All regressions show a positive SST anomaly over the central and eastern Pacific, indicating that ENSO is the dominant mechanism causing variations in the southern moisture influx over these regions. An anticyclonic anomaly is found over the western North Pacific (not shown). These findings are consistent with Wang et al. (2000), who attributed the formation of this anticyclonic anomaly to both the local SST cooling over the western North Pacific and the remote SST warming over the central Pacific, which can be seen in Fig. 8. The positive correlation coefficients between the Niño 3.4 index and the southern moisture influxes of these regions also reflect this relationship (Table 2). The increased moisture is transported to the EA landmass via the southerly winds along the western flank of the anticyclonic anomaly.

In JJA, the moisture influxes via the southern boundaries of regions 1, 2 and 3 have significant positive correlations with precipitation variability. The regression coefficients of the vertically integrated moisture fluxes regressed onto these moisture influxes are shown in Fig. 9a-c. The moisture fluxes show an anticyclonic anomaly over the EA coast that affects the southern boundary of each region. This anticyclonic anomaly is local and is not obviously linked to the central tropical Pacific where SST anomalies are weak. This local feature has been noted in previous studies, which have linked it to a combination of the local wind-evaporation-SST feedback over the western North Pacific and the propagation of a Kelvin wave due to tropical Indian Ocean warming (Wang et al. 2003; Xie et al. 2009; Wu et al. 2010). The positive SST anomalies over the Tropical Indian Ocean and the South China Sea are linked to the southern moisture influxes to regions 1 and 2 but not to region 3 (Fig. 9d-f). This lack of association between tropical SST anomalies and higher latitude circulation variations was also observed in previous studies (e.g., Xie et al. 2016). Instead, the moisture influx anomaly over region 3 is associated with local SST variability, particularly in the Kuroshio Current extension region.

In SON, the moisture influx variations over the southern boundary of each region are associated with a circumglobal wave pattern in the Northern Hemisphere. The source regions of the perturbation may vary from one occurrence of the wave pattern to another (Stephan et al. 2017).

\subsection{Evaporation}

The role of evaporation in precipitation interannual variability varies by region and season. As summarised in Table 1, evaporation is negatively correlated with precipitation over region 1 in JJA. It is positively correlated with precipitation over region 2 in DJF and MAM, region 3 in MAM and region 4 in MAM, JJA and SON.

The impact of evaporation on precipitation reflects the strength of the land-atmosphere coupling. Previous studies (Koster et al. 2004; Seneviratne et al. 2010) showed that stronger land-atmosphere coupling preferentially occurs in the transition regions between wet and dry soil moisture 

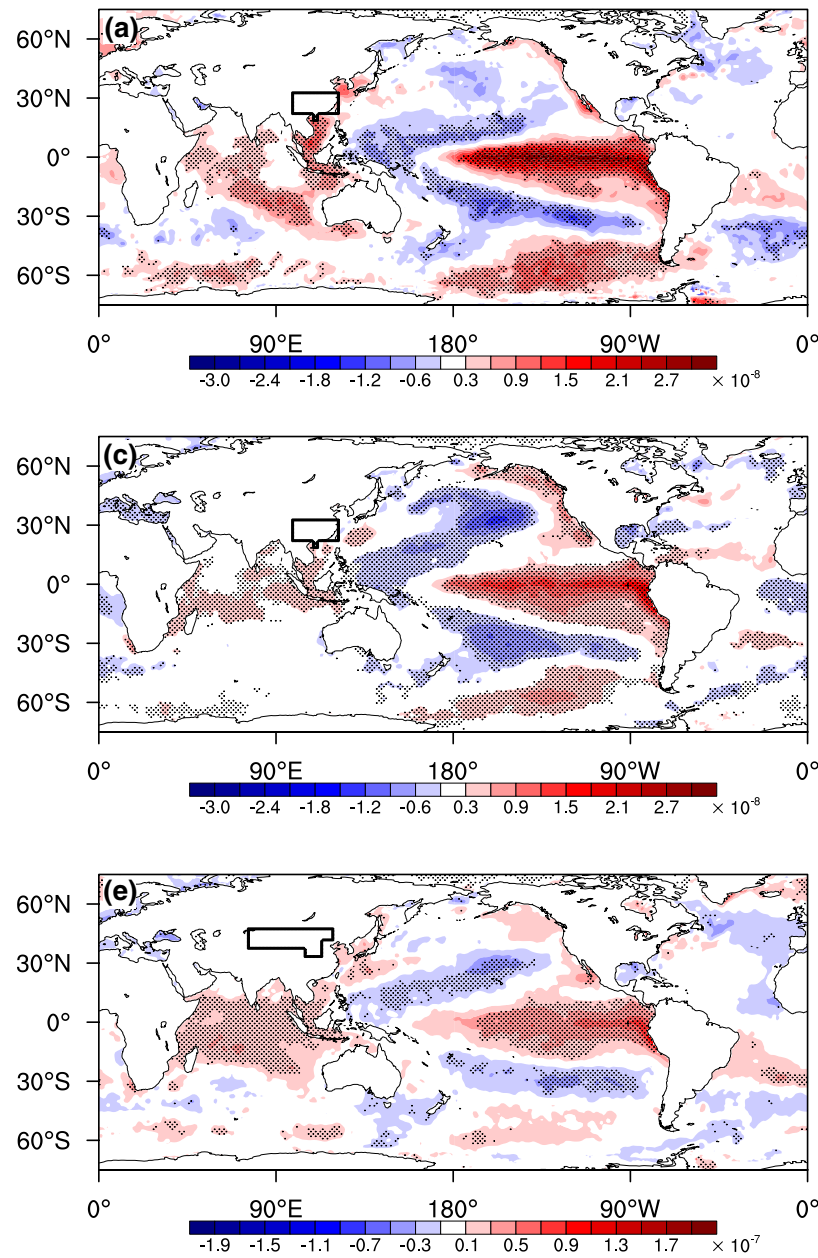

Fig. 8 Regression coefficients of SST regressed onto the moisture influx across the south boundaries of regions 1 (a) and 3 (b) in DJF during 1979-2012. Regression coefficients of SST regressed onto the

zones. To identify the transition regions over EA, we show the correlation coefficients of the seasonal mean daily maximum $2 \mathrm{~m}$ temperature and the seasonal mean evaporation, $r\left(T_{2, \max }, E\right)$, calculated from ERA-Interim during 1979-2012 (Figure 10). Seneviratne et al. (2006, 2010) found that, on monthly-to-annual scales, $r\left(T_{2, \max }, E\right)$ is an adequate diagnostic to reveal land-atmosphere coupling strength. Over transitional regions, $r\left(T_{2, \max }, E\right)$ is characterised by negative values, while over wet regions, $r\left(T_{2, \max }, E\right)$ is characterised by positive values. The negative $r\left(T_{2, \max }, E\right)$ over transitional regions is due to a negative feedback: increased surface temperature leads to a higher vapour pressure deficit and evaporative demand; under relatively dry conditions, this decreases soil moisture; which decreases evaporation, which in turn increases the surface temperature and the sensible heat flux.

As shown in Fig. 10, significant negative $r\left(T_{2, \max }, E\right)$ values are located mainly over regions 3 and 4 . This demonstrates that regions 3 and 4 are transitional regions and that
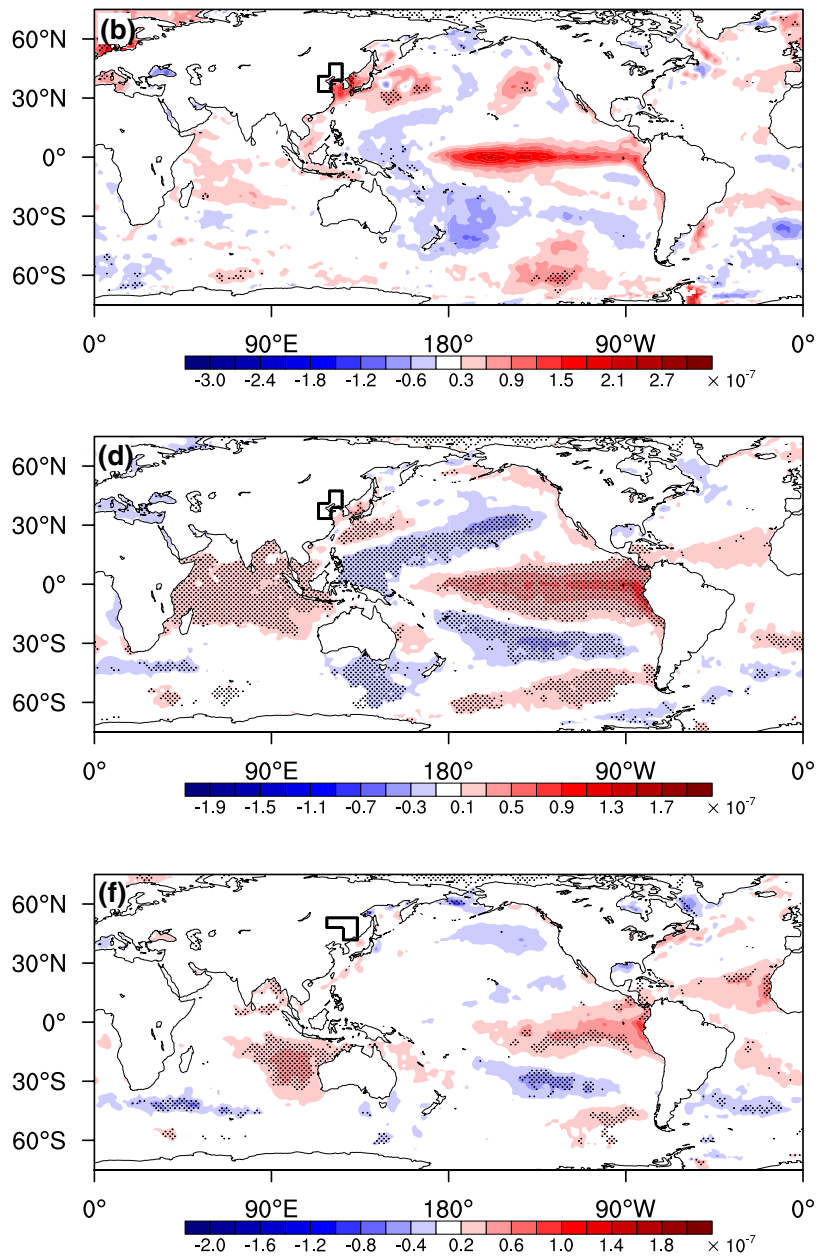

moisture influx across the south boundaries of regions 1 (c), 3 (d), 4 (e) and 5 (f) in MAM during 1979-2012. Regression coefficients exceed the $90 \%$ confidence level are stippled. Units: $\mathrm{K} /(\mathrm{kg} / \mathrm{s})$

the evaporation over these regions has a strong impact on the precipitation, which is consistent with the correlation coefficients shown in Table 1. Region 1, however, shows positive $r\left(T_{2, \max }, E\right)$. This indicates a negative correlation between evaporation and precipitation, which is consistent with Table 1. With ample soil moisture due to the EASM in JJA, evaporation is constrained by the surface energy budget rather than by soil moisture. During a precipitation event, increased cloud cover reduces net surface shortwave radiation and evaporation. This negative correlation between evaporation and precipitation over southeastern China was also found in other studies (Wei et al. 2012; Hua et al. 2017).

Over region 2, evaporation dominates precipitation variability in DJF and MAM. This is in line with previous studies (van der Ent et al. 2010; Hua et al. 2017) that suggested that the topography confines the local evaporation within the region. However, it is interesting to notice the contrasting $r\left(T_{2, \max }, E\right)$ values between the western and eastern TP in MAM, JJA and SON. This indicates a dry western TP and a 

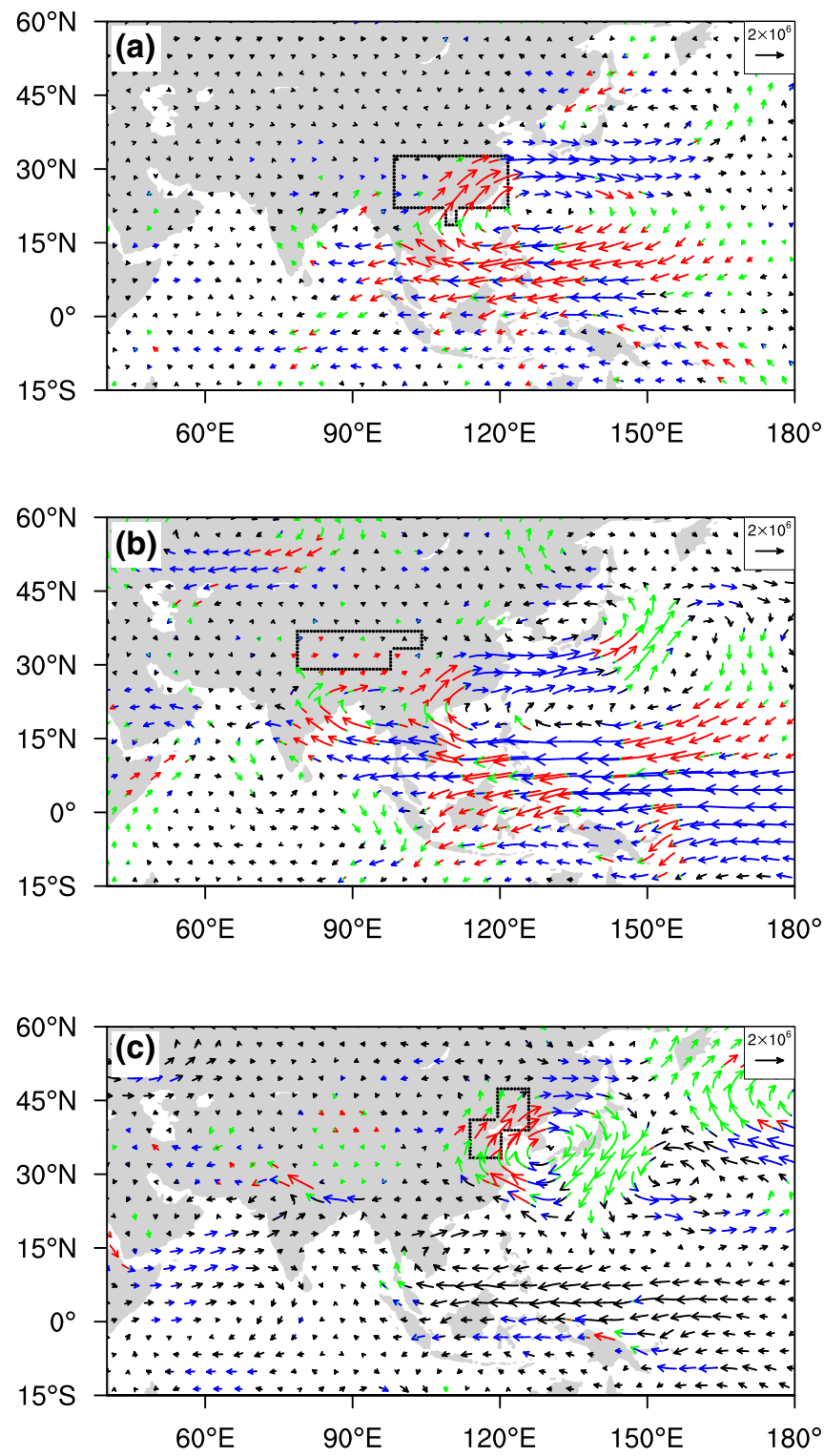

Fig. 9 a-c Regression coefficients of the vertically integrated moisture flux regressed onto the moisture influx across the south boundaries of regions 1, 2 and 3 during JJA 1979-2012. Units: $(\mathrm{kg} / \mathrm{m} / \mathrm{s}) /$ $(\mathrm{kg} / \mathrm{s})$. Colours indicate that the regression coefficients are significant at the $90 \%$ confidence level: blue indicates that the regression coefficient of zonal moisture flux is significant; green indicates that the

wet eastern TP. One possible explanation for this is the difference in the orientation of the topography. In the western TP, the Himalayas lie to the south and are zonally oriented, allowing them to block moisture transported from the relatively moist Indian subcontinent and the Bay of Bengal. In the eastern TP, the Himalayas are oriented meridionally, which allows a stronger moisture transport from the south, higher precipitation and wetter soils (Curio et al. 2015).
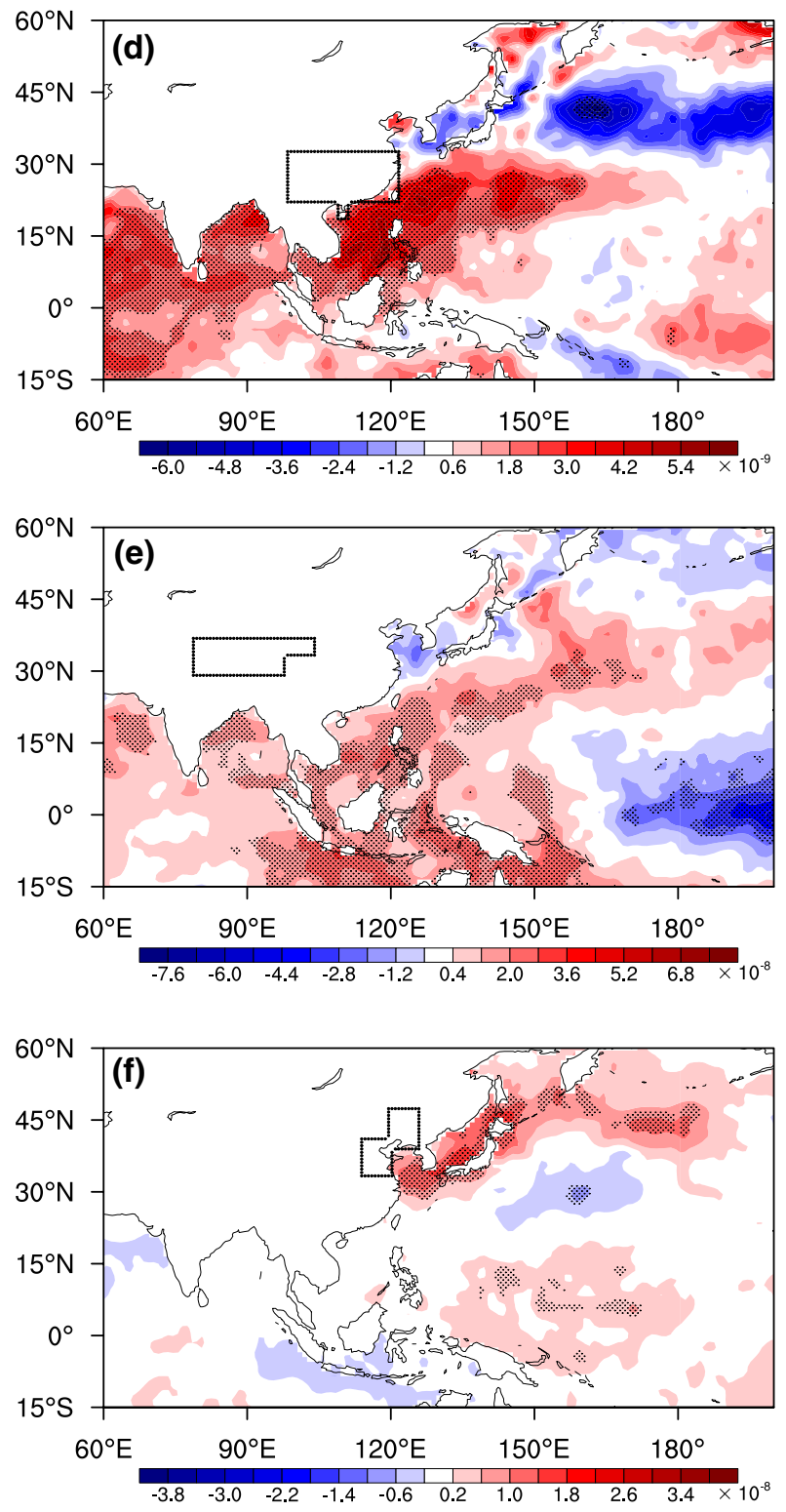

regression coefficient of meridional moisture flux is significant; red indicates that regression coefficients of both directions are significant. d-f Regression coefficients of SST regressed onto the moisture influx across the south boundaries of regions 1, 2 and 3 during JJA 19792012. Units: $\mathrm{K} /(\mathrm{kg} / \mathrm{s})$. Regression coefficients that exceed the $90 \%$ confidence level are stippled

\section{Discussion}

We discuss the limitations of the B1993 method, followed by a discussion on the uncertainties of the hydrological variables in ERA-Interim over EA, and the choice of study regions. 
Fig. 10 Seasonal mean correlation coefficients between the seasonal mean daily maximum $2 \mathrm{~m}$ temperature and the evaporation $r\left(E, T_{2, \max }\right)$ using ERAInterim during 1979-2012. Values that exceed the $90 \%$ confidence level are stippled. Units: 1
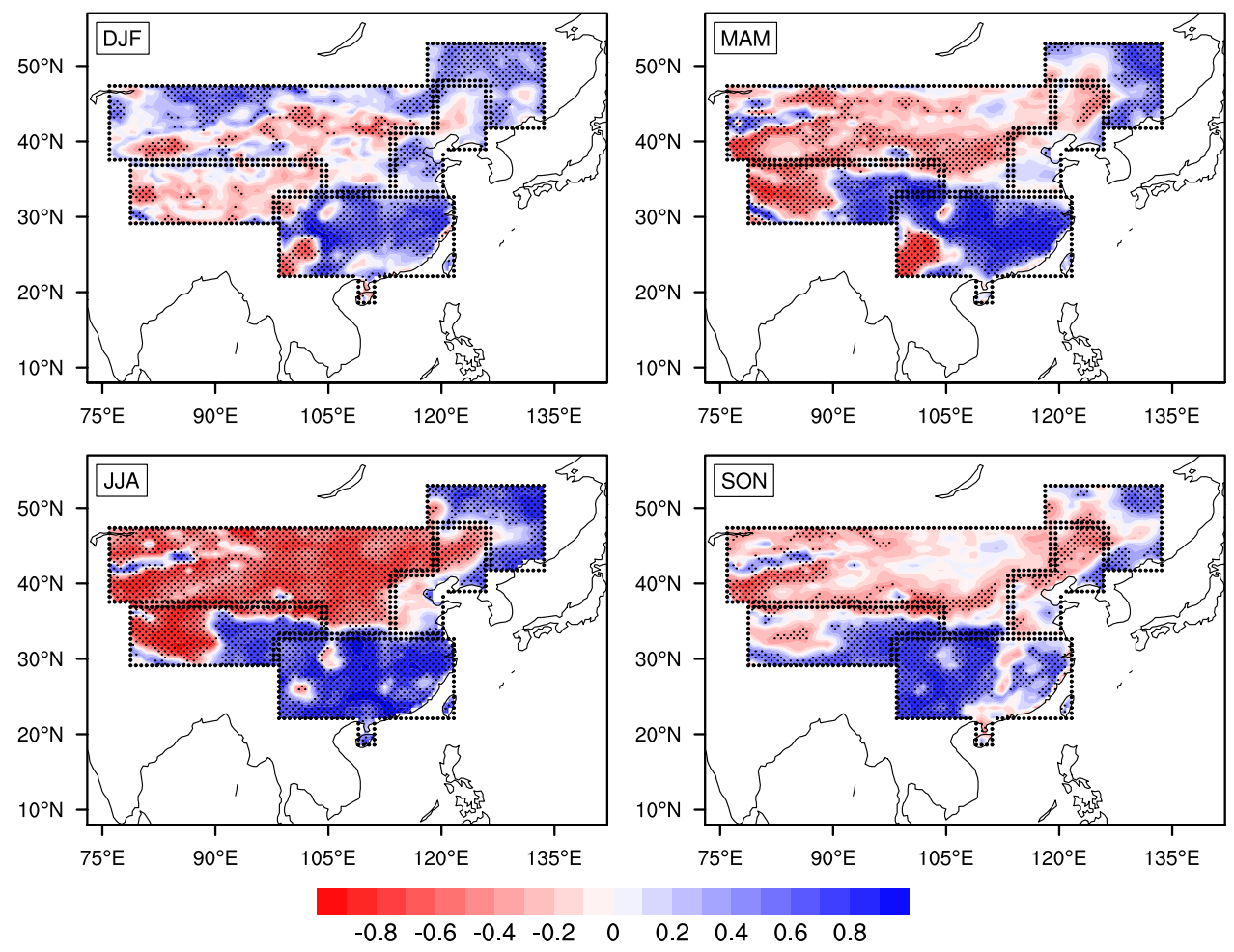

\subsection{Limitations in the B1993 method used here}

We use the B1993 method to compute $\rho$. The B 1993 method was originally designed for parallel flow. The moisture transport over EA does not strictly fit the assumption of parallel flow. However, throughout the year (except SON) over EA land, the moisture flux is relatively parallel with weak rotation (figure not shown). The convergence of the moisture flux is mainly due to the decrease of the moisture flux along the flow rather than to its rotation. Therefore, the parallel flow assumption of B1993 is reasonably valid over EA.

Several studies have reported that the B1993 method underestimates $\rho$ (Schär et al. 1999; Savenije 1995; Dirmeyer and Brubaker 1999). However, whether the B1993 method underestimates $\rho$ depends on the region under study. Over the Sahel, Savenije (1995) argue that the B1993 method underestimates $\rho$. Over southeastern North America, however, the magnitude of $\rho$ calculated from B 1993 is comparable to that calculated from an on-line 3-D water vapour tracer method (Bosilovich and Schubert 2002).

The B1993 method is comparable to other analytic methods over other regions that have similar sizes and shapes to the regions defined here, e.g., the Amazon Basin, the Mississippi Basin and Europe (Eltahir and Bras 1996; Burde and Zangvil 2001). Furthermore, we also applied a numerical vapour tracing method to compute the $\rho$ over these five regions: the Water Accounting Model (van der Ent et al. 2010). The $\rho$ calculated from the B1993 method is also comparable to the $\rho$ from the Water Accounting Model over the EA; more details about this comparison will be reported in a future study.

The B1993 method offers a simple calculation of $\rho$ (Eq. 1) as a function of only moisture influx and local evaporation, $\rho=\rho\left(F^{i n}, E\right)$. It is interesting to note that $\rho$ and the related precipitation in a region are determined from $F^{\text {in }}$ rather than the net moisture flux that is widely used in precipitationrelated studies, because both the net moisture flux and $P$ minus $E$ are directly related to the moisture convergence. In fact, the B1993 method uses the net moisture flux, however, due to the introduction of the third assumption, the

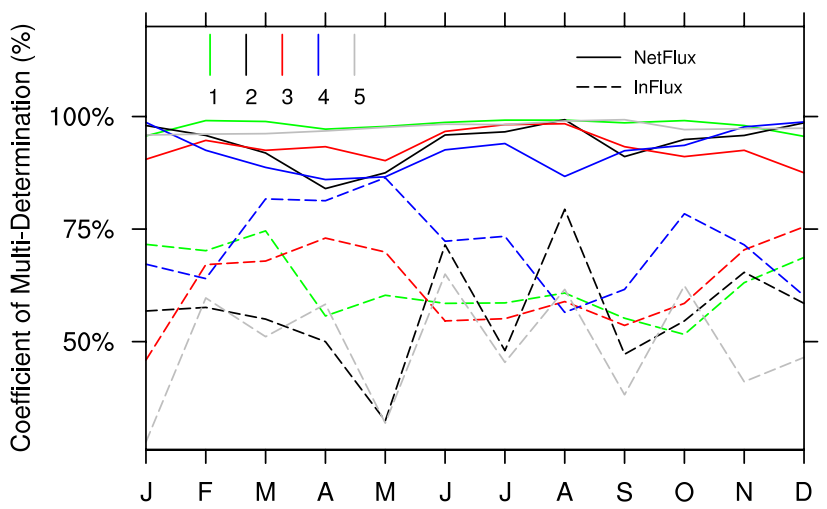

Fig. 11 Coefficient of multi-determination calculated from moisture influxes (dash lines) and from moisture net fluxes (solid lines) for regions $1-5$. Units: \% 
net moisture flux becomes a linear function of the moisture influx (as shown in Eqs. 6 and 7). This linear relationship simplifies the B1993 method and makes possible our expansion to the contributions from the moisture fluxes from each direction.

However, a limitation is inevitably introduced by the fact that neither $P$ nor $E$ are constant across the study regions. To investigate this limitation, we use the coefficient of multi-determination $R^{2}$ introduced in Sect. 2.2. Figure 11 shows the $R^{2}$ calculated from the net moisture flux $R_{n e t}^{2}$ and from the moisture influx $R_{i n}^{2}$. $R_{n e t}^{2}$ is close to $100 \%$ for all five regions throughout the year, indicating that the net moisture flux across the boundaries can explain almost all the precipitation interannual variability. $R_{i n}^{2}$ ranges mainly between 50 and $75 \%$, indicating that about $50-75 \%$ of the precipitation interannual variability can be explained by the moisture influx across boundaries. There is no doubt that the net moisture flux across the boundaries has a closer link to precipitation variability. However, decomposing the net moisture flux into the contribution from each direction would be less informative than our decomposition of the moisture influx. This is because the net moisture flux across any one boundary is a combination of the moisture influx across that boundary and the moisture outflux across that boundary, the latter of which is related to the moisture influxes on all other boundaries, including the local evaporation. Any variation in the net moisture flux across one boundary cannot be attributed to a change in the moisture transport from only that direction. This makes links between circulation anomalies and variability of the net moisture flux from a particular direction less convincing. Although the moisture influx is not perfect in terms of explaining precipitation variation, the variations of moisture influx across a particular boundary can be more clearly linked to atmospheric circulation anomalies. This allows the identification of potential mechanisms to understand those variations.

\subsection{Trajectory analysis}

Trajectory analysis of the origins of moisture for precipitation is a useful technique to understand regional hydrological variability, as shown in previous studies (e.g., Gimeno et al. 2012; Dirmeyer and Brubaker 1999; de Leeuw et al. 2017). It is mainly achieved through a Lagrangian method or through integrating the atmospheric water conservation equation backwards in time, either on-line in an atmospheric model or off-line using data from model integrations. A key objective of this study is to identify the connections between moisture fluxes and inter-annual atmospheric variability. For this purpose, the extension of B1993 we present is more than suitable. Moreover, the analytic method we present is much less computationally demanding than Lagrangian trajectory methods or methods that integrate the atmospheric water conservation equation. Our analytic method uses only monthly data, rather than the daily or sub-daily data required by trajectory methods, which means that our method can be readily applied to a wider range of models and datasets to investigate regional hydrological features. To verify the results shown in this study, we are applying the Water Accounting Model (van der Ent et al. 2010; van der Ent and Savennije 2011) to identify the sources of moisture for precipitation in the five sub-regions defined in this study. Comparisons between these methods will be reported in the near future.

\subsection{Uncertainty of ERA-Interim hydrological variables over $E A$}

Although we chose ERA-Interim for its higher fidelity in reproducing the hydrological budget and its interannual variability (Trenberth et al. 2011), uncertainty in the hydrological budget remains over China in ERA-Interim. For example, over region 3 during spring and autumn, the $P-E$ over land is slightly negative (Fig. 1), which is at odds with the physical constraint that $P-E$ over land must be positive as runoff must be positive. Also, there are large differences in the mean annual cycle of precipitation over region 2 (TP) between ERA-Interim and GPCP (Fig. 2). This overestimate of precipitation over TP in ERA-Interim has been reported in previous studies (Tong et al. 2013); it is a common issue for reanalyses (You et al. 2015), especially in the southeastern TP where summer convection dominates.

Part of these biases may be linked to the imbalance of the hydrological budget in the reanalyses. It is partly due to the model bias, and partly due to the observational uncertainties introduced via data assimilation schemes (Trenberth et al. 2011). As pointed out by Rodell et al. (2015), the hydrological storage terms and fluxes are observed individually in remote sensing. Although each observation falls within the anticipated error bounds, the absence of balance constraints among these components causes imbalance in the hydrological budget as well as in the related surface energy budget (L'Ecuyer et al. 2015).

\subsection{Dividing the study regions}

Note that both the size and shape of the region affects the estimation of contributions to the precipitation, especially for $\rho$. The precipitation recycling ratio tends to be greater for a larger domain, if the hydrological conditions remain similar. Besides, as pointed out by van der Ent and Savennije 
(2011), if the domain is a rectangle, $\rho$ will be smaller in a region whose major axis is perpendicular to the moisture flux, relative to a region whose major axis is parallel to the moisture flux. This study does not aim to compare $\rho$ among these five regions, but to separate the contributions to precipitation from advected and evaporated moisture, independently for each region. Using an analytic model with idealised assumptions may introduce certain inaccuracies, but the potential links between variability in precipitation, evaporation and large-scale atmospheric circulation can still be clearly identified.

\section{Summary}

In this study, we identified the contributions of local and remote atmospheric moisture influxes to East Asian precipitation and its interannual variability. First, we divided China into five regions — southeast, Tibetan Plateau (TP), central east, northwest and northeast-according to hydrological features and topography, then calculated the regional precipitation recycling ratio of each region using the method of Brubaker et al. (1993). Based on the regional precipitation recycling ratio and other hydrological variables, we show in Fig. 3 the hydrological cycle for each region and derived the regional evaporation recycling ratio and conversion ratio for advected atmospheric moisture. The precipitation recycling is highest over the TP, the northwest and the southeast.

We expanded the Brubaker et al. (1993) method to estimate the contributions to precipitation in each region from the moisture influxes from each direction. Over the southeast, the moisture influx via the southern boundary dominates the mean precipitation throughout the year. In particular, the southern moisture influx provides over $60 \%$ of the moisture for the mean precipitation in MAM and JJA. Over the TP, the southern moisture influx is also a major contributor in JJA and SON, however, it is not as dominant in other seasons as over the southeast. Instead, the moisture influx via the western boundary dominates in DJF and MAM. Over the central east, northwest and northeast, the western moisture influx is the major contributor throughout the year, with the southern moisture influx controlled by the summer monsoon in JJA.

Further, we investigated the relationship between the precipitation and the moisture influx (including the local evaporation) on interannual scales. Results show that the major moisture sources that contribute to the mean precipitation are not necessarily the key contributors to the precipitation interannual variability over the same region. Over the TP in DJF and MAM, the local evaporation has the highest correlation with the precipitation interannual variation. Over the central east, northwest and northeast, although the western moisture influx dominates the mean precipitation, the variations in the southern and northern moisture influxes and the local evaporation are the major contributors to the precipitation interannual variation, depending on the season.

We identified potential mechanisms that may control the variations in the moisture influxes from each direction. On the western boundary, in DJF over the northwest, the variation of the moisture influx is linked to the NAO. On the northern boundary, in DJF over both the southeast and northeast, the variations of moisture influxes are linked to opposite phases of the AO. On the southern boundary, the variations of moisture influxes of most regions are linked to ENSO. The variations of local evaporation have a higher correlation over the northwest and the central east regions, where the soil moisture is limited and the land-atmosphere coupling is strong.

The methods and results discussed in this study could be used to evaluate climate model simulations of the regional hydrological cycle. Simulation of precipitation is one of the most essential and most challenging tasks in weather and climate modelling. The complex links between precipitation and other physical and dynamical processes make it difficult to identify the causes of precipitation biases in models. In this study, we tried to break this complex link into two simple parts. The first is the link between precipitation and moisture influxes (from each direction, including local evaporation); the second is the link between moisture influxes and the atmospheric circulation. This breakdown may be useful to evaluate precipitation in weather and climate models. The first link reveals the moisture sources for regional precipitation and its variations. If this link is well represented in the models, then the second link can reveal whether the first link is associated with the correct atmospheric circulations and their variations. If the models simulate both links but have not simulated the correct precipitation in a region, then the sources of precipitation bias in the models could be due to incorrect representations of local physical processes, e.g., errors in the treatment of boundarylayer and convective processes and cloud microphysics.

Acknowledgements This work and its contributors were supported by the UK-China Research \& Innovation Partnership Fund through the Met Office Climate Science for Service Partnership (CSSP) China as part of the Newton Fund. NPK was also funded by a UK Natural Environment Research Council Independent Research Fellowship (NE/ L010976/1). GPCP Precipitation data provided by the NOAA/OAR/ ESRL PSD, Boulder, Colorado, USA, from their web site at http:// www.esrl.noaa.gov/psd/. UK Meteorological Office, Hadley Centre. HadISST 1.1 - Global sea-Ice coverage and SST (1870-Present). British Atmospheric Data Centre, 2006, available from http://badc.nerc. ac.uk/data/hadisst/.

Open Access This article is distributed under the terms of the Creative Commons Attribution 4.0 International License (http:// 
creativecommons.org/licenses/by/4.0/), which permits unrestricted use, distribution, and reproduction in any medium, provided you give appropriate credit to the original author(s) and the source, provide a link to the Creative Commons license, and indicate if changes were made.

\section{References}

Adler RF, Huffman GJ, Chang A, Ferraro R, Xie PP, Janowiak J, Rudolf B, Schneider U, Curtis S, Bolvin D, Gruber A, Susskind J, Arkin P, Nelkin E (2003) The version-2 Global Precipitation Climatology Project (GPCP) monthly precipitation analysis (1979 Present). J Hydrometeorol 4:1147-1167. https://doi. org/10.1175/1525-7541(2003)004\%3c1147:TVGPCP\%3e2.0 . $\mathrm{CO} ; 2$

Berrisford P, Dee D, Poli P, Brugge R, Fielding K, Fuentes M, Kallberg P, Kobayashi S, Uppala S, Simmons A (2011) The ERA-Interim archive version 2.0. ERA Report Series. ECMWF, Shinfield Park, Reading

Bosilovich MG, Schubert SD (2002) Water vapor tracers as diagnostics of the regional hydrologic cycle. J Hydrometeorol 3:149165. https://doi.org/10.1175/1525-7541(2002)003\%3c0149:W VTADO\%3e2.0.CO;2

Brubaker KL, Entekhabi D, Eagleson PS (1993) Estimation of continental precipitation recycling. J Clim 6:1077-1089. https:// doi.org/10.1175/1520-0442(1993)006\%3c1077:EOCPR\%3e2. $0 . \mathrm{CO} ; 2$

Burde GI, Zangvil A (2001) The estimation of regional precipitation recycling. Part I: review of recycling models. J Clim 14(12):24972508. https://doi.org/10.1175/1520-0442(2001)014\%3c2497:TE ORPR\%3e2.0.CO;2

Chen B, Xu XD (2015) Spatiotemporal structure of the moisture sources feeding heavy precipitation events over the Sichuan Basin. Int J Climatol 36:3446-3457. https://doi.org/10.1002/joc.4567

Curio J, Maussion F, Scherer D (2015) A 12-year high-resolution climatology of atmospheric water transport over the Tibetan Plateau. Earth Syst Dyn 6:109-124. https://doi.org/10.5194/ esd-6-109-2015

de Leeuw J, Methven J, Blackburn M (2017) Physical factors influencing regional precipitation variability attributed using an airmass trajectory method. J Clim 30:7359-7378. https://doi.org/10.1175/ JCLI-D-16-0547.1

Dee DP, Uppala SM, Simmons AJ, Berrisford P, Poli P, Kobayashi S, Andrae U, Balmaseda MA, Balsamo G, Bauer P, Bechtold P, Beljaars ACM, van de Berg L, Bidlot J, Bormann N, Delsol C, Dragani R, Fuentes M, Geer AJ, Haimberger L, Healy SB, Hersbach $\mathrm{H}, \mathrm{EVH}$ lm, Isaksen L, llberg PK, hler MK, Matricardi M, McNally AP, Monge-Sanz BM, Morcrette JJ, Park BK, Peubey C, de Rosnay P, Tavolato C, pauta JNT, Vitarta F (2011) The ERA-Interim reanalysis: configuration and performance of the data assimilation system. Q J R Meteorol Soc 137(656):553-597. https://doi.org/10.1002/qj.828

Dirmeyer PA, Brubaker KL (1999) Contrasting evaporative moisture source during the drought of 1998 and the flood of 1993. J Geophys Res 104:19,383-19,397. https://doi. org/10.1029/1999JD900222

Dominguez F, Kumar P, Liang XZ, Ting M (2006) Impact of atmospheric moisture storage on precipitation recycling. J Clim 19:1513-1530. https://doi.org/10.1175/JCLI3691.1

Domroes M, Peng G (1988) The climate of China. Springer, Berlin, Heidelberg. https://doi.org/10.1007/978-3-642-73333-8

Drumond A, Nieto R, Gimeno L (2011) Sources of moisture for China and their variations during drier and wetter conditions in 20002004: a Lagrangian approach. Clim Res 50:215-225
Eltahir EAB, Bras RL (1996) Precipitation recycling. Rev Geophys 34(3):367-378. https://doi.org/10.1029/96RG01927

Feng L, Zhou T (2012) Water vapor transport for summer precipitation over the Tibetan Plateau: multidata set analysis. J Geophys Res 117:D20,114. https://doi.org/10.1029/2011JD017012

Findell KL, Gentine P, Lintner BR, Kerr C (2011) Probability of afternoon precipitation in eastern United States and Mexico enhanced by high evaporation. Nat Geosci 4:434-439. https:// doi.org/10.1038/ngeo1174

Gat JR, Garmi I (1970) Evolution of the isotopic composition of atmospheric waters in the Mediterranean sea area. J Geophys Res 75:3039-3048. https://doi.org/10.1029/JC075i015p03039

Gimeno L, Stohl A, Trigo RM, Dominguez F, Yoshimura K, Yu L, Drumond A, Durn-Quesada AM, Nieto R (2012) Oceanic and terrestrial sources of continental precipitation. Rev Geophys 50:RG4003. https://doi.org/10.1029/2012RG000389

Goessling HF, Reick CH (2011) What do moisture recycling estimates tell us? Exploring the extreme case of non-evaporating continents. Hydrol Earth Syst Sci 15:3217-3235. https://doi.org/10.5194/ hess-15-3217-2011

Gong DY, Ho CH (2002) The Siberian high and climate change over middle to high latitude Asia. Theor Appl Climatol 72:1-9. https:// doi.org/10.1007/s007040200008

Gong DY, Wang SW, Zhu JH (2001) East Asian winter monsoon and Arctic oscillation. Geophys Res Lett 28(10):2073-2076. https:// doi.org/10.1029/2000GL012311

Guillod BP, Orlowsky B, Miralles D, Teuling AJ, Blanken PD, Buchmann N, Ciais P, Ek M, Findell KL, Gentine P, Lintner BR, Scott RL, den Hurk BV, Seneviratne SI (2014) Land-surface controls on afternoon precipitation diagnosed from observational data: uncertainties and confounding factors. Atmos Chem Phys 14:83438367. https://doi.org/10.5194/acp-14-8343-2014

Hua L, Zhong L, Ke Z (2017) Characteristics of the precipitation recycling ratio and its relationship with regional precipitation in China. Theor Appl Climatol 127(3):513-531. https://doi. org/10.1007/s00704-015-1645-1

Huang Y, Cui X (2015) Moisture sources of torrential rainfall events in the Sichuan Basin of China during summers of 200913. J Hydrometeorol 16:1906-1917. https://doi.org/10.1175/ JHM-D-14-0220.1

Huang R, Wu Y (1989) The influence of ENSO on the summer climate change in China and its mechanism. Adv Atmos Sci 6(1). https:// doi.org/10.1007/BF02656915

Keys PW, Barnes EA, van der Ent RJ, Gordon LJ (2014) Variability of moisture recycling using a precipitationshed framework. Hydrol Earth Syst Sci 18:3937-3950. https://doi.org/10.5194/ hess-18-3937-2014

Koster RD, Dirmeyer PA, Guo Z, Bonan G, Chan E, Cox P, Gordon CT, Kanae S, Kowalczyk E, Lawrence D, Liu P, Lu CH, Malyshev S, McAvaney B, Mitchell K, Mocko D, Oki T, Oleson K, Pitman A, Sud YC, Taylor CM, Verseghy D, Vasic R, Xue Y, Yamada T (2004) Regions of strong coupling between soil moisture and precipitation. Science 305(5687):1138-1140. https://doi.org/10.1126/ science. 1100217

L'Ecuyer TS, Beaudoing HK, Rodell M, Olson W, Lin B, Kato S, Clayson CA, Wood E, Sheffield J, Adler R, Huffman G, Bosilovich M, Gu G, Robertson F, Houser PR, Chambers D, Famiglietti JS, Fetzer E, Liu WT, Gao X, Schlosser CA, Clark E, Lettenmaier DP, Hilburn K (2015) The observed state of the energy budget in the early twenty-first century. J Clim 28:8319-8346. https://doi. org/10.1175/JCLI-D-14-00556.1

Li X, Zhou W (2012) Quasi-4-Yr coupling between El Nin oSouthern oscillation and water vapor transport over East Asia WNP. J Clim 25:5879-5891. https://doi.org/10.1175/JCLI-D-11-00433.1 
Li X, Zhou W, Chen YD (2015) Assessment of regional drought trend and risk over China: a drought climate division perspective. J Clim 28:7025-7037. https://doi.org/10.1175/JCLI-D-14-00403.1

Lin R, Zhou T, Qian Y (2014) Evaluation of global monsoon precipitation changes based on five reanalysis datasets. J Clim 27:12711289. https://doi.org/10.1175/JCLI-D-13-00215.1

Li X, Wen Z, Zhou W (2011) Long-term change in summer water vapor transport over South China in recent decades. https://doi. org/10.2151/jmsj.2011-A17

Ma S, Zhou T, Dai A, Han Z (2015) Observed changes in the distributions of daily precipitation frequency and amount over China from 1960 to 2013. J Clim 28:6960-6978. https://doi.org/10.1175/ JCLI-D-15-0011.1

Rayner NA, Parker DE, Horton EB, Folland CK, Alexander LV, Rowell DP, Kent EC, Kaplan A (2003) Global analyses of sea surface temperature, sea ice, and night marine air temperature since the late nineteenth century. J Geophys Res 108(D14):4407. https:// doi.org/10.1029/2002JD002670

Rodell M, Beaudoing HK, LEcuyer TS, Olson WS, Famiglietti JS, Houser PR, Adler R, Bosilovich MG, Clayson CA, Chambers D, Clark E, Fetzer EJ, Gao X, Gu G, Hilburn K, Huffman GJ, Lettenmaier DP, Liu WT, Robertson FR, Schlosser CA, Sheffield J, Wood EF (2015) The observed state of the water cycle in the early twenty-first century. J Clim 28:8289-8318. https://doi. org/10.1175/JCLI-D-14-00555.1

Savenije HHG (1995) New definition for moisture recycling and relationship with land-use changes in the Sahel. J Hydrol 167. https:// doi.org/10.1016/0022-1694(94)02632-L

Schär C, Lüthi D, Beyerle U (1999) The soil-precipitation feedback: a process study with a regional climate model. J Clim 12:722-741. https://doi.org/10.1175/1520-0442(1999)012\%3c0722:TSPFAP $\% 3 \mathrm{e} 2.0 . \mathrm{CO} ; 2$

Seneviratne S, Luthi D, Litschi M, Schr C (2006) Landatmosphere coupling and climate change in Europe. Nature 443:205-209. https:// doi.org/10.1038/nature05095

Seneviratne SI, Corti T, Davin EL, Hirschi M, Jaeger EB, Lehner I, Orlowsky B, Teuling AJ (2010) Investigating soil moistureclimate interactions in a changing climate: A review. Earth-Sci Rev 99:125-161. https://doi.org/10.1016/j.earscirev.2010.02.004

Stephan CC, Klingaman NP, Vidale PL, Turner AG, Demory ME, Guo L (2017) A comprehensive analysis of coherent rainfall patterns in China and potential drivers. Part I: interannual variability. Clim Dyn Publ Onlinehttps://doi.org/10.1007/s00382-017-3882-8

Stohl A, James P (2004) A Lagrangian analysis of the atmospheric branch of the global water cycle. Part I: method description, validation, and demonstration for the august 2002 Ffooding in Central Europe. J Hydrometeorol 5:656-678. https://doi. org/10.1175/1525-7541(2004)005\%3c0656:ALAOTA\%3e2.0 .CO;2

Su T, Feng T, Feng G (2015) Evaporation variability under climate warming in five reanalyses and its association with pan evaporation over China. J Geophys Res 120(6):8080-8098. https://doi. org/10.1002/2014JD023040

Sun B, Wang H (2013) Water vapor transport paths and accumulation during widespread snowfall events in Northeastern China. J Clim 26:4550-4566. https://doi.org/10.1175/JCLI-D-12-00300.1

Sun B, Wang H (2014) Moisture sources of semiarid grassland in China using the Lagrangian particle model FLEXPART. J Clim 27:2457-2474. https://doi.org/10.1175/JCLI-D-13-00517.1

Taylor CM, de Jeu RAM, Guichard F, Harris PP, Dorigo WA (2012) Afternoon rain more likely over drier soils. Nature 489:423-426. https://doi.org/10.1038/nature11377

Tong K, Su F, Yang D, Zhang L, Hao Z (2013) Tibetan Plateau precipitation as depicted by gauge observations, reanalyses and satellite retrievals. Int J Climatol 34(2):265-285. https://doi.org/10.1002/ joc. 3682
Trenberth KE (1999) Atmospheric moisture recycling: role of advection and local evaporation. J Clim 12:1368-1381. https://doi. org/10.1175/1520-0442(1999)012\%3c1368:AMRROA\%3e2.0 $\mathrm{CO} ; 2$

Trenberth KE, Fasullo JT, Mackaro J (2011) Atmospheric moisture transports from ocean to land and global energy flows in reanalyses. J Clim 24:4907-4924

van der Ent RJ, Savennije HHG (2011) Length and time scales of atmospheric moisture recycling. Atmos Chem Phys 11:18531863. https://doi.org/10.5194/acp-11-1853-2011

van der Ent RJ, Savenije HHG, Schaefli B, SteeleDunne SC (2010) Origin and fate of atmospheric moisture over continents. Water Resour Res 46:W09,525. https://doi.org/10.1029/2010WR009127

Wang B, Wu R, Fu X (2000) PacificEast Asian Teleconnection: how does ENSO Affect East Asian Climate? J Clim 13:1517-1536. https://doi.org/10.1175/1520-0442(2000)013\%3c1517:PEATH $\mathrm{D} \% 3 \mathrm{e} 2.0 . \mathrm{CO} ; 2$

Wang B, Wu R, Li T (2003) AtmosphereWarm ocean interaction and its impacts on AsianAustralian monsoon variation. J Clim 16:1195-1211. https://doi.org/10.1175/1520-0442(2003)16\%3c11 95:AOIAII\%3e2.0.CO;2

Wei J, Dirmeyer PA, Bosilovich MG, Wu R (2012) Water vapor sources for Yangtze River Valley rainfall: climatology, variability, and implications for rainfall forecasting. J Geophys Res 117:D05,126. https://doi.org/10.1029/2011JD016902

Wu B, Li T, Zhou T (2010) Relative contributions of the Indian Ocean and local SST anomalies to the maintenance of the Western North Pacific anomalous anticyclone during the El Niño decaying summer. J Clim 23:2974-2986. https://doi.org/10.1175/201 OJCLI3300.1

Wu B, Wang J (2002) Winter Arctic Oscillation. Siberian High and East Asian Winter Monsoon. https://doi.org/10.1029/2002GL015373

Xie SP, Hu K, Hafner J, Tokinaga H, Du Y, Huang G, Sampe T (2009) Indian Ocean capacitor effect on Indo-Western Pacific climate during the summer following El Nino. J Clim 22:730-747. https:// doi.org/10.1175/2008JCLI2544.1

Xie SP, Kosaka Y, Du Y, Hu K, Chowdary JS, Huang G (2016) IndoWestern Pacific Ocean capacitor and coherent climate anomalies in Post-ENSO summer: a review. Adv Atmos Sci 33:411-432. https://doi.org/10.1007/s00376-015-5192-6

You Q, Min J, Zhang W, Pepin N, Kang S (2015) Comparison of multiple datasets with gridded precipitation observations over the Tibetan Plateau. Clim Dyn 45:791-806. https://doi.org/10.1007/ s00382-014-2310-6

Zhai P, Zhang X, Wan H, Pan X (2005) Trends in total precipitation and frequency of daily precipitation extremes over China. J Clim 18:1096-1108. https://doi.org/10.1175/JCLI-3318.1

Zhang C, Tang Q, Chen D (2016) Recent changes in the moisture source of precipitation over the Tibetan Plateau. Journal of Climate in press. https://doi.org/10.1175/JCLI-D-15-0842.1

Zhao T, Zhao J, Hu H, Ni G (2016a) Source of atmospheric moisture and precipitation over Chinas major river basins. Front Earth Sci 10(1):159-170. https://doi.org/10.1007/s11707-015-0497-4

Zhao Y, Xu X, Zhao T, Xu H, Mao F, Sun H, Wang Y (2016b) Extreme precipitation events in East China and associated moisture transport pathways. Sci China Earth Sci 59:1854-1872. https://doi. org/10.1007/s11430-016-5315-7

Zhou TJ, Yu RC (2005) Atmospheric water vapor transport associated with typical anomalous summer rainfall patterns in China. J Geophys Res 110:D08,104. https://doi.org/10.1029/2004JD005413

Zhu Y (2003) The Regional Division of Dryness/Wetness over Eastern China and variations of dryness/wetness in Northern China during the last 530 years. Acta Geogr Sin 58:100-107 